OPEN ACCESS

Edited by:

Jan Van den Stock, KU-Leuven, Belgium

Reviewed by: Rory Allen,

Goldsmiths University of London,

United Kingdom

Michal Przemyslaw Muszynski, Université de Genève, Switzerland

*Correspondence:

Radoslaw Niewiadomski radoslaw.niewiadomski@iit.it

Specialty section: This article was submitted to Emotion Science, a section of the journal Frontiers in Psychology

Received: 30 September 2019 Accepted: 30 April 2020 Published: 15 July 2020

Citation

Larradet F, Niewiadomski R, Barresi G, Caldwell DG and Mattos LS (2020) Toward Emotion Recognition From Physiological Signals in the Wild: Approaching the Methodological Issues in Real-Life Data Collection. Front. Psychol. 11:1111. doi: 10.3389/fpsyg.2020.01111

\section{Toward Emotion Recognition From Physiological Signals in the Wild: Approaching the Methodological Issues in Real-Life Data Collection}

\author{
Fanny Larradet ${ }^{1}$, Radoslaw Niewiadomski ${ }^{2,3 *}$, Giacinto Barresi ${ }^{4}$, Darwin G. Caldwell ${ }^{1}$ and \\ Leonardo S. Mattos ${ }^{1}$ \\ ${ }^{1}$ Advanced Robotics, Istituto Italiano di Tecnologia, Genoa, Italy, ${ }^{2}$ Contact Unit, Istituto Italiano di Tecnologia, Genoa, Italy, \\ ${ }^{3}$ Department of Psychology and Cognitive Science, University of Trento, Rovereto, Italy, ${ }^{4}$ Rehab Technologies, Istituto \\ Italiano di Tecnologia, Genoa, Italy
}

Emotion, mood, and stress recognition (EMSR) has been studied in laboratory settings for decades. In particular, physiological signals are widely used to detect and classify affective states in lab conditions. However, physiological reactions to emotional stimuli have been found to differ in laboratory and natural settings. Thanks to recent technological progress (e.g., in wearables) the creation of EMSR systems for a large number of consumers during their everyday activities is increasingly possible. Therefore, datasets created in the wild are needed to insure the validity and the exploitability of EMSR models for real-life applications. In this paper, we initially present common techniques used in laboratory settings to induce emotions for the purpose of physiological dataset creation. Next, advantages and challenges of data collection in the wild are discussed. To assess the applicability of existing datasets to real-life applications, we propose a set of categories to guide and compare at a glance different methodologies used by researchers to collect such data. For this purpose, we also introduce a visual tool called Graphical Assessment of Real-life Application-Focused Emotional Dataset (GARAFED). In the last part of the paper, we apply the proposed tool to compare existing physiological datasets for EMSR in the wild and to show possible improvements and future directions of research. We wish for this paper and GARAFED to be used as guidelines for researchers and developers who aim at collecting affect-related data for real-life EMSR-based applications.

\footnotetext{
Keywords: emotion recognition, data collection, in-the-wild, physiological signals, emotion elicitation and assessment
}

\section{INTRODUCTION}

Emotion, mood and stress recognition (EMSR) ${ }^{1}$ from facial expression (Fasel and Luettin, 2003), speech (El Ayadi et al., 2011), full-body motion (Kleinsmith and Bianchi-Berthouze, 2013), text (Hirschberg and Manning, 2015), and physiological signals (Jerritta et al., 2011) has been studied intensively for at least two decades. The EMSR models can be differentiated according to the emotion theory adopted to characterize the data. While using labels such as anger, disgust, fear,

\footnotetext{
${ }^{1}$ All abbreviations are explained in the Supplementary Materials.
} 
joy, sadness, and surprise present the advantages of being meaningful to non-experts, many researchers use multidimensional models such as valence-arousal (Russell, 1980) or pleasure-arousal-dominance (Mehrabian, 1996) to classify emotions in a 2 or 3 dimensional space. Appraisal theories such as the Ortony, Clore \& Collins (OCC) model (Ortony et al., 1990) or Ira Roseman's theory (Roseman, 1984), which explain emotion elicitation in terms of cognitive evaluations of significant events, are still rarely exploited in recognition and detection studies. As for the classification method, most works use approaches based on feature extraction and machine learning (e.g., Support Vector Machine) (Hovsepian et al., 2015), decision trees (Plarre et al., 2011), while solutions based on expert knowledge (e.g., rulebased) are more rare. Recently deep learning methods have been applied (e.g., convolutional deep belief networks, Ranganathan et al., 2016). The latter are, however, still limited by the capacity to collect a sufficient amount of data. EMSR methods might be userdependent (or person-specific), built from the data of a specific user to detect his/her own emotions, or user-independent, built from the data of multiple users to detect emotions of any user. Regardless of the emotion theory and classification method used, one of the biggest challenges in EMSR consists in collecting and annotating data for both model creation and testing (Constantine and Hajj, 2012). In this paper, we address this challenge by providing a thorough discussion of existing methodologies for dataset creation as well as proposing evaluation criteria and tools to compare datasets and develop new ones. While most of EMSRs use similar methods to collect the affect related data, in this paper we focus on physiological signals.

So far, building physiological datasets for EMSR was usually performed in laboratory settings by purposely inducing emotions in subjects at specific time intervals. It allows experimenters to control the stimuli and reduce the number of contextual factors that may influence the subjects' reactions. To date, few studies have attempted to create real-life (not induced) emotions datasets, i.e., collections of affect-related data, outside of the lab, in reaction to everyday events. In the literature, the terms "in the wild" (Dhall et al., 2013), "in the fray" (Healey et al., 2010), and "in real-life" (Devillers et al., 2005) are used to describe such approach, in which the experimenters do not control the emotion elicitation process. In this methodology, the subjects can be, for example, monitored during their everyday activities over long time periods in order to collect their natural reactions. This kind of study can either be ambulatory (Healey et al., 2010) where people are able to move freely, or static where people experience real-life emotions but constrained to a specific location [e.g., a desk in a workplace (McDuff et al., 2012) or during an exam (Melillo et al., 2011)]. This similarity to real-life settings defines the ecological validity of a study (Ladouce et al., 2017).

There exist several potential applications of the EMSR for "real-life applications", i.e., methods able to recognize emotions, moods or stress, in the wild (not induced, elicited by real-life events). Let us consider two examples of such an applications. The first example (Example 1) would be a smartphone mobile application designed to be a personal life coach. Such app would be able to detect the users' emotions helping them to become more aware of their own feelings, and to develop a more positive attitude toward life and healthy habits (Woodward et al., 2019). In this specific case, a EMSR module would be needed to recognize the users' real-life emotions, e.g., while they perform any activity, therefore, in an ambulatory setting. This EMSR model should be functional for any user desiring to acquire such a system.

The second example (Example 2) of such real-life application would be a system aiming at detecting real-life emotions for patients with Locked-in Syndrome (LIS). Such patients are unable to move any muscles beside the eyes and are unable to speak (Smith and Delargy, 2005). Consequently these patients would benefit from any system that allows them to communicate with the others, including the communication of emotions. For instance, the LIS patients were positive about the system enabling them to communicate explicitly emotions through a gaze-controlled system endowed of an avatar able to "display" the patients' emotions though facial expressions and voice. Such communication can be facilitated having an EMSR model working in-the-wild. In the case of building EMSR system for LIS patients, in theory there is no need to be concerned about ambulatory challenges. In practice, however, it might be difficult to find enough number of patients in this state to build a robust EMSR model, i.e., the model that works for every patient. Additionally, it might be unethical and difficult to involve such patients in long data collections and early testing stages of the model. In this case preliminary testing might be required with subjects without motor impairments, and, thus, probably performed in ambulatory settings. Only in the last step, such model would be adapted to the LIS patients.

In this paper, we take the perspective of the researcher or software developer who needs (1) to create a new dataset to be used for EMSR or (2) to build a EMSR model on top of existing dataset. We discuss the issues related to creation of "reallife application"-oriented datasets. We compare different data collection methods enumerating their advantages, challenges and limitations. In particular, we focus on physiological data collection outside of the laboratory as it represents a way to access people's emotional state without invading their privacy (e.g., using video, audio) and without being cumbersome (thanks to the size of the sensors). This paper presents a set of guidelines that may be used to build physiological datasets for EMSR. In order to facilitate the comparison and evaluation of such studies, we introduce a visual method to assess EMSR studies in terms of their ability to be used in real-life applications. This graphical method is used to visually compare the existing data collections. We then present an overview of the studies that take a step toward creation of EMSR based on physiological data collected outside of the laboratory.

While some reviews on emotion recognition from physiological signals exist (Jerritta et al., 2011) including systematic reviews (Kreibig, 2010; Wac and Tsiourti, 2014), the aim of this work is focused on showing the variety of methods and issues related to data collection in-the-wild. Therefore, we favored a broad-spectrum description of related works rather than a detailed list of stress-related datasets. Within this perspective, this paper can be of interest not only to experts in Affective Computing and Artificial Intelligence targeting 
development of new EMSR systems, but also researchers in Psychology. The comparative analysis of previous research related to data collection for emotion recognition in-the-wild is extremely important both for the design of future EMSR-based digital applications and for psychology research, as it highlights their strengths and weaknesses regarding their validity in real life situations. Furthermore, by analyzing previous studies from this point of view, the paper offers a sort of guideline for the design of novel experiments regarding emotions in the wild, which we believe can be valuable for researchers working on Emotion Science.

The main contributions of the paper are:

- While other recent surveys on EMSR make a census by considering expressive modality (e.g., El Ayadi et al., 2011; Kleinsmith and Bianchi-Berthouze, 2013), this work brings a new point of view to the field by focusing on methodologies for physiological data collection to build real-life EMSR applications in the wild.

- We propose a complete list of criteria as well as a novel graphical aid to compare and evaluate any existing and future affect-related datasets in terms of their applicability in real-life applications.

The paper is organized as follows: In section 2, we review existing data collection techniques by presenting emotion elicitation methods. In section 3, we present the in-the-wild methodology by discussing its advantages and disadvantages compared to traditional methods. In section 4, we present the categories and the visual aid chosen in this paper to assess the presented papers. Finally, in section 5, the existing studies on emotion, stress and mood recognition in the wild using physiological data alone or associated with other modalities are presented. Currently (1st July 2019) available commercial devices for ambulatory physiological data collecting are listed in the annex.

\subsection{Related Works}

Some works were published recently that survey emotion recognition from the physiological signals. Wac and Tsiourti (2014) provided systematic review of the wearable systems used to assess the affect in ambulatory conditions. The authors provide the deep analysis of the recently developed devices and propose also the list criteria for the device choice which include the study duration, number of participants, methods of ground truth assessments, whether the assessment can be performed online or offline, as well as compliance with technical standards.

Aiming at finding specific ANS responses for distinct emotional states (Kreibig, 2010) surveyed 134 empirical studies. In total 16 emotions (i.e., 6 basic emotions, 8 additional positive emotions, anxiety and suspense) were considered, and for each of them the authors sum up all observed ANS responses in different studies. Recently Shu et al. (2018) provided un updated survey of computational methods applied to physiological signals for emotion recognition In that work the authors listed different methods of emotion induction, capturing ANS signals, signal processing and feature extraction, fusion, and the large range of classification algorithms. Regarding surveys of existing datasets,
Valstar (2019) reviewed recently existing multimodal databases, mainly focusing on audio-visual data.

Compared to above mentioned works, in this paper we focus more on the process of data collection as well the data annotation, and we try to provide a set of criteria to assess existing and future ones.

\section{COMMON EMOTION ELICITATION TECHNIQUES USED FOR DATA COLLECTION}

While the remainder of paper is focused on physiological signals, established techniques to elicit emotions are common for collecting other types of signals (Kory and D'Mello, 2015). We start this short survey by mentioning current techniques, in which there is no emotion elicitation protocol at all, as the participants do not actually feel any affective state but only pretend to react in an emotional way. These techniques often involve the participation of actors who act emotion expressions through facial expressions, body movements and speech (Wallbott and Scherer, 1986). Several researchers, however, claim that the spontaneous expressions of emotions are different from acted ones. For instance, Hoque et al. (2012) found significant differences in facial expressions of acted and induced emotions. Consequently, the EMSR models trained on acted data may not work properly in real-life applications. Using actors seems not to be viable for physiological signals collections as people may not be able to simulate their own physiological reactions. Actors may use some techniques such as the Stanislavski's method (Cole, 1995) to make their acting more natural. Other methods of self-induction of emotion have been used in scientific literature: e.g., in Vrana (1993) subjects are asked to apply the guided imagery method that consists in thinking about specific situations to elicit emotions. Retrospection is another commonly used techniques where participants are asked to narrate a story from their past when they experienced a given emotional state (e.g., Pasupathi, 2003).

Other studies on emotion, mood or stress try to induce more genuine reactions in their participants by using validated experimental protocols. These usually consist of exposing the subjects to some pre-defined and pre-validated stimuli for emotion induction. In such studies the experimenter has control over the environment such as the type, duration, order of the stimulus and the position of subject (e.g., whether he is sitting or standing). For instance, the widely used IAPS database (Lang et al., 2008) contains 956 images chosen to induce emotions and rated on valence and arousal by 100 participants. It was used in a great number of studies (Dikecligil and MujicaParodi, 2010; Fox et al., 2010; Schmidt et al., 2011; Walter et al., 2011). Other example-the Geneva affective picture database (GAPED) (Dan-Glauser and Scherer, 2011)—contains 730 pictures similarly rated. Also open-access annotated datasets of movie extracts exist. Some of them are explicitly created to induce specific emotional states in viewers, while others made for automatic analysis of affective content in a movie (by extracting some scene characteristics such as lightness, quantity 
of motion etc.). Independently of their primary aim, both types might be useful to evoke emotions in-the-lab conditions and collect the physiological data. The examples are the LIRISACCEDE dataset (Baveye et al., 2015) containing continuous annotations of arousal and valence, and FilmStim (Schaefer et al., 2010) annotated with 6 discrete labels. Other more specific datesets include "the emotional film database for Asian culture" (Deng et al., 2017), which was validated through physiological measurements, or the E-MOVIE dataset (Maffei and Angrilli, 2019) composed of the movie extracts of fixed duration making them suitable for psycho-physiological research. Interestingly, the latter is annotated not only with emotion dimensions but also with discrete emotion labels.

Artwork is a greatly used tool for emotion induction. For instance, showing some extracts of well-known movies (such as The Pianists, Mr. Bean) was the method adopted by Soleymani and colleagues to create the MAHNOB-HCI dataset (Soleymani et al., 2011). Rooney et al. (2012) established that 3D movies have an enhanced capacity to create arousal and emotion when compared with traditional 2D movies. Within performing arts the physiological data of the performer can be also collected. For instance, Niewiadomski et al. (2017) and Lussu et al. (2019) explored whether the respiration signal captured by a standard microphone placed near to mouth can be used to classify the expressive movements. For this purpose, they collected the respiration data of dancers performing the sequences of expressive movements.

Music stimuli have also been used in a few studies (Kim and André, 2008; Konečni, 2008; Kreutz et al., 2008). They are often associated with other inputs such as light and storytelling (Kim et al., 2004). Similarly as for the visual stimuli, several audio based datasets have been created that can be used to generate affectrelated physiological data collections. The examples include a dataset of 110 film music excerpts annotated with discrete labels, and arousal, valence dimensions (Eerola and Vuoskoski, 2011) used to induce emotions by Vuoskoski and Eerola (2011) and DEAM (Aljanaki et al., 2017). More recently it has been shown that also other artistic activities may convey emotional and physiological reactions in the wild e.g., watching the painting (Tschacher et al., 2012) and making the painting (HaiblumItskovitch et al., 2018). Thus, they can potentially be used for the data collection purposes.

Methods requiring active participation of subjects were also used, e.g., by using video games (Tognetti et al., 2010), virtual reality (Ververidis et al., 2008) and more recently immersive VR-games (Bassano et al., 2019). The latter uses a system composed of a VR-game and software platform to collect the player's physiological data. The data recordings are synchronized with the VR content presented to a player, so it is possible to trace which games events evoke specific physiological reactions. In particular, to evoke specific emotions, the VR-game was designed following the emotion elicitation process described by Roseman's appraisal theory (Roseman, 1984).

Annotating interfaces such as PAGAN (Melhart et al., 2019) or CARMA (Girard, 2014) (see section 3.3.2.2 for more details on annotation tools) have been developed to collect affect ratings by participants experiencing medias. However, researcher must be careful when using the movie or audio extracts as an emotion induction method, as it was found that perceived emotions by the observer (i.e., interpretation of the movie content, e.g., emotions of a movie character perceived by the observer) do not always agree with induced emotions (i.e., emotions felt by the observer)-both when using video (Muszynski et al., 2019) and audio (Kallinen and Ravaja, 2006).

Other less common emotion induction methods e.g., guided activation of specific facial muscles or postures (without being aware of corresponding affect) (Zajonc et al., 1989), can be found in the literature. These are based on facial feedback theories (Tomkins, 1962; Izard, 1977) according to which posing the facial expression, which corresponds to the specific emotion, may induce the corresponding emotional state in the person performing it. Researchers tried also to induce emotions by creating social scenarios in the lab simulating some realistic social interactions. For instance, Harmon-Jones and Sigelman (2001) asked the participants to write about an important subject to them, which was then negatively rated (regardless of the content) by a second participant. An aggressive comment and a low mark was expected to induce anger in the subjects. This type of study, especially the one focusing on negative emotions, usually requires that the participant is not aware of the experimental procedure. Niewiadomski et al. (2016) elicited expressions of amusement by having participants playing social games with their friends in the lab. Amodio et al. (2007) presents additional guidelines for building such scenarios such as a the elaboration of a credible cover story, a constant experimenter behavior and the conduct of post-experimental interviews.

Avatars, virtual agents and social robots have also been used to create highly controlled experimental social scenarios. The big advantage of using these technologies is that they can replace the human partner and be used to generate sequences of stimuli for multiple human participants in simulated social interaction scenarios. Meanwhile, the experimenter can maintain control over the stimuli generation (e.g., verbal and non-verbal behaviors of such the virtual agents/avatars/robots, timing, turn-taking etc.) and it the same procedure can be easily repeated it with a large number of participants. For instance, AlZoubi et al. (2012) used an avatar to induce boredom confusion and curiosity for expression detection. Turner-Cobb et al. (2019) measured the physiological reactions during a stressful task consisting of performing a mock interview in front of a robot audience. Shortcomings of this methodology should also be mentioned, including the fact that creation of realistic human-like non-verbal behaviors by artificial agents is still a significant challenge.

Other researchers have tried to collect spontaneous affective reactions while controlling the experimental environment by performing supervised real-life studies. These consist of putting the subjects into situations that usually bring about a strong emotional reactions e.g., sky-diving (Dikecligil and MujicaParodi, 2010) or driving in difficult conditions (Healey et al., 2005).

To introduce stress, additional techniques are available (Karthikeyan et al., 2011). The Stroop test from 1935 (Stroop, 1935)-presenting words representing a color written in a different color and asking to verbally state the written 
color-have been used in many studies (Pehlivanoğlu et al., 2005; Zhai and Barreto, 2006). Hassellund et al. (2010) used a cold stressor, which consists in immerging one's hand in cold water. Other popular stress induction stimuli include, for instance, performing mental arithmetic exercises (Ring et al., 2002), voluntary hyperventilation (De Santos Sierra et al., 2011), public speaking (Von Dawans et al., 2011), or computer games (Rani et al., 2002).

The previously presented techniques all have their own set of advantages and limitations. They will be further discussed in comparison with the in-the-wild methodology in next section.

\section{THE IN-THE-WILD METHODOLOGY}

\subsection{Why Are Datasets In-the-Wild Needed?}

A large number of studies on automatic emotion recognition from physiological signals obtained good recognition rates (Jerritta et al., 2011) but very few of the proposed methods were then tested on data collected in the wild. Their applicability in real-life applications is therefore not confirmed.

Wilhelm and Grossman (2010) presented the risks of such approaches in terms of physiological signals, comparing laboratory induced stress and the ones occurring in ecological settings. They studied the case of physiological reaction to stress and compared laboratory induced stress to real-life ones such as watching a soccer game. They found the heart rate during the latter was elevated significantly compared to the former. Similarly, Xu et al. (2017) considered the validity of using in the lab collected data for ambulatory emotion detection. Their findings suggested that EDA, ECG, and EMG greatly differ between real-life and laboratory settings and that using such methodologies result in low recognition rates (17-45\%). Thus, it is necessary to validate EMSR methods in the wild to be able to automatically recognize people's emotional states in reallife applications, such as the ones introduced in section 1 . Additionally, even if emotion laboratory induction techniques use a highly controlled experimental procedure there is no certainty that the subjects will actually experience the desired emotion. Indeed, people can react differently to the same stimuli (Kret and De Gelder, 2012). For instance, one person might enjoy horror movies and find the experience entertaining, while someone else might find it scary and stressful. This might also be the reason why common passive methods of emotion induction, e.g., image datasets (see section 2) usually focus only on small subsets of "basic" emotions or arousal-valence dimensions. More subtle or complex emotions (e.g., guilt, pride) are probably more person-specific.

Furthermore, it is known that people's physiological signals adapt with age (Kostis et al., 1982) or fitness level (Melanson and Freedson, 2001). User-dependent EMSR systems may then need either to use adaptive models to include such changes or to allow the users to periodically re-train the model which may be difficult for models based on in-the-lab data (see section 3.2.3).

Using in-the-wild data for both the model building and testing phases brings additional advantages. Firstly, using in-the-wild data allows for iterative learning. By using data collected in the wild to build a model, it becomes possible to improve the models over time. This approach requires the use of in-the-wild data collection combined with self-reporting (see section 3.3.2.1).

Secondly, as mobiles phones and personal sensors become more and more popular, this data collection approach also allows the usage big data (Laurila et al., 2012) allowing the application of the latest techniques of data mining and deep learning. Indeed, model created from users self-report input and real-life emotions could allow for the collection of an extensive dataset. People are already reporting their emotion on mobile apps for the sole purpose of self-monitoring (e.g., "The Mood Meter"2, "Pixelsmental self awareness"3, "Mood diary"4). There is only a small step to associate such data labeling to physiological sensors using mobile applications. Preliminary work toward this aim was recently proposed in Larradet et al. (2019).

\subsection{Advantages}

In order to present the advantages of the in-the-wild methodology, we compare it with the previously presented techniques for data collection in the lab (see section 2).

\subsubsection{Ethical Issues}

Inducing negative emotions such as anger or sadness can be problematic due to some ethical constraints. Usually only low intensity emotion induction methods such as IAPS images or movie clips (see section 2) are acceptable to Ethical Committees. The model would therefore not be able to learn from high intensity reactions as they would not be present in the collected dataset. On the other hand, real-life emotions collected using the in-the-wild methodology can be of any level of intensity and valence.

\subsubsection{Context}

Although the creation of emotion elicitation procedures in the lab usually allows for a better control of the context (by minimizing unrelated factors that may influence the emotion elicitation process), several other factors may alter the affective reactions. For instance, some participants may already feel stressed or uncomfortable when participating in an experimental study in a laboratory (Britton et al., 1983). Emotions collected in the wild appear in a natural context without the presence of an experimenter to alter the subject's affects.

\subsubsection{Experimental Effort}

Whether the data collection is performed in the lab or in the wild, an effort is necessary to build the dataset. In the laboratory, the experimenters need to prepare and validate the experimental protocol for emotion elicitation (e.g., trying interactive scenarios, preparing emotion induction games, finding appropriate images datasets, see more in section 2). In the wild, this effort is given to the subjects that need to report their emotions. In this case, no effort is required from the experimenter as the stressors/emotional situations are provided by life itself.

User-dependent EMSR models are often used in the case of physiological signals because of the important interpersonal

\footnotetext{
${ }^{2}$ https://moodmeterapp.com

${ }^{3}$ https://play.google.com/store/apps/details?id=ar.teovogel.yip\&hl=en_US

${ }^{4} \mathrm{https} / /$ play.google.com/store/apps/details?id=info.bdslab.android.moodyapp
} 
differences in people's baselines and reactions to stimuli. Therefore, they tend to give better emotion classification results (Jerritta et al., 2011). However, for the reasons mentioned in section 3.1 an EMSR model may need to be updated after some time, and there is a need to reproduce the data collection and emotion elicitation process. For most emotion induction methods cited earlier (see section 2), it is difficult and probably ineffective to reproduce the method using the same set of stimuli. The previous knowledge of the stimuli may reduce or totally suppress the emotional reaction. Therefore a new set is then needed to repeat the emotion induction and data collection. It is, therefore, difficult to use an user-dependent induced emotions datasets to train EMSR models to be used over longer time periods, as it requires time consuming interventions (i.e., new stimuli preparation and new data collection) each time the EMSR model needs to be updated.

On the other hand, since user-dependent EMSR models built using the in the wild methodology only need self-reporting effort from the user and do not need any stimuli preparation. They can be updated, when the user requests it and agrees to self-report additional data. Consequently, this approach seems more suitable for real-life applications (e.g., the two examples mentioned in section 1).

\subsection{Challenges and Limitations}

\subsubsection{Absence of a Controlled Environment}

In-lab data collection provides a controlled environment, that is similar for all the subjects. It allows for the comparison of many subjects' reactions to similar stimuli. Using a real-life dataset implies an unknown environment. The experimenter is unable to predict the emotional stimuli that will occur. Additionally, those stimuli will most likely be different for all subjects which makes inter-subject data comparison difficult. For instance, two subjects might experience happiness, but one due to an accepted scientific publication and the other because of a conversation with a friend. While both emotional reactions will be labeled as "happy," they appeared in different contexts and are caused by different events. Because of this unpredictability and lack of a control over the data collection procedure, the experimenter is a priori unaware of the emotions felt by the subjects, and therefore this information needs to be determined a posteriori. Several ways of acquiring such information will be presented in the next section.

\subsubsection{Emotion Labeling}

There are two main methods to acquire information about the data of affect-related events in an uncontrolled environment:

\subsubsection{Self-report}

The most commonly used data labeling technique is controlled by the subjects themselves. In this method, participants are asked to report the time in which they felt an emotion, which emotion, and, eventually, some other parameters such as its intensity or context. This emotion self-labeling should be performed following specific emotion theory or framework. One can, for instance, report emotions using a set of discrete emotion labels (Zenonos et al., 2016), estimate valence and arousal (Carroll et al., 2013), or report significant potentially emotion-relevant events in terms of appraisals (Larradet et al., 2019). Each of these methods, brings challenges. For instance, it may be difficult for the subjects to estimate arousal as it is a concept that nonexpert are usually unfamiliar with. Consequently their report might not be reliable. Indeed, Healey et al. (2010) found that subjects' valence and arousal reports did not correlate with their comments. They identified that subjects misunderstood the 2 dimensional map and interpreted the axis origin as 0 arousal instead of medium arousal. Techniques such as the SAM images (Bradley and Lang, 1994) are often used to make the selfreporting task more intuitive. Also, asking the subjects to selfreport emotions by using labels such as "angry" or "sad" can also lead to problems. Indeed, Widen and Russell (2010) highlighted the need for a distinction between "descriptive definition" of emotion, as it is used in everyday life, and a "prescriptive definition", as it is used by the scientific community. Similarly, the label understanding might differ within participants due to gender (Kret and De Gelder, 2012), or cultural differences (Mesquita et al., 1997). These differences might influence the quality of the dataset and, consequently, alter the capacity to automatically recognize emotions especially in the case of userindependent EMSR model. Larradet et al. (2019) addressed this problem and used an appraisal theory-based questionnaire to help the subjects provide precise information about the emotion elicitation events, without the need for them to pick a specific emotion label.

Oversight is another problem derived from subjects labeling their own data. One may not immediately report the felt emotion and then, simply forget to do it. Depending on the application, rating the emotion in terms of intensity might also be necessary. However, subjects might underrate their emotions for several reasons, e.g., they may not admit that they felt sad or scared. Additionally, emotion self-reports tend to be less valid when performed a long time after the experienced emotion (Mauss and Robinson, 2009).

Furthermore, user-given annotation of emotions beginning and end times might not be precise. Subjects will tend to give approximate times, making the exact data labeling more difficult. Instead of asking the subject to voluntarily report emotions when they feel them, some studies use technology-enhanced methods (e.g., smartphone apps, or sending emails) to prompt the user to report emotions at regular intervals. This method is often called Ecological Momentary Assessment (EMA) (Shiffman et al., 2008) or Fixed Time-Based strategies (Wac and Tsiourti, 2014). For instance, it is used in Plarre et al. (2011) to collect physiological signals and self-reports in a natural environment over a 2 day period. In this experiment, the phone app periodically prompted the user to complete self-report questionnaires on their stress levels and emotions being experienced.

It is not clear, however, what is the optimal frequency of such prompting. Plarre et al. (2011) mention that their app prompted the users 25 times per day on average, however, asking too often can easily become bothersome to the subjects and therefore affect the quality of the self-reporting. Asking too rarely would increase the chance that the subject will report lower intensity of the emotion (Mauss and Robinson, 2009), or forgot to report. Schmidt et al. (2018) suggest performing an 
EMA every $2 \mathrm{~h}$ or five times a day coupled with the possibility to manually report emotions. When prompting regularly the subjects to self-report their emotions over certain period of the time (e.g., every hour), the collected information about the timing (i.e., when emotion started and ended) of reported states might not be precise. Thus, this technique may be more appropriate to collect information about moods which often have a longer duration (Mauss and Robinson, 2009), rather than emotions that are usually short (Gray et al., 2001). Indeed, Robinson and Clore (2002) states that increasing the time between two consecutive prompts increases the chances to collect semantic (related to beliefs and generalizations about oneself) memory of emotions instead of episodic (related to a particular event) ones. Accessing events details of the day may improve the recall (Lang et al., 1980; Robinson and Clore, 2001). However, retrospective thinking about too many details may disproportionately bias the emotional report (Kahneman et al., 1999). Asking subjects details about their daily lives might not meet the ethical regulations as it provides an easy way to recognize the subject. Asking the subjects to mentally reproduce the event without providing any information to the experimenter about it, might be a solution (Clore et al., 2001).

\subsubsection{Expert labeling}

This method involves having one or several experts examine the data and use their knowledge and expertise to annotate emotions. This can be achieved using either the same physiological signal(s) as those that will be used in the EMSR model (Yin et al., 2006) or using a different type of signal (e.g., facial expressions, body movements). For instance, Healey et al. (2005) conducted an experiment where both physiological signals and video data were recorded in the wild. The video was analyzed by experts to validate the data labels given by the subjects and physiological data was used later to create an emotion detection model. However, this method often requires multimodal synchronized recordings which can be difficult to gather in-the-wild. The modalities which are most often used by experts when performing the annotation, such as video or audio, are usually the most intrusive.

Additionally, if more than one expert performs the annotation, they may disagree on perceived emotions. Consequently several methods were proposed to compute the inter-rater agreement and inter-rater reliability such as Cohen's or Fleiss's Kappa. The other approach may consist of a combination of expert labeling and user post-experiment cross-validation (Yin et al., 2006). Independent of the issues related to the collection of the synchronized video or audio data for the purpose of the expert annotation and labeling, several tools were created to help experts to annotate such data offline. Recent examples include PAGAN (Melhart et al., 2019) or ANVIL (Kipp, 2012). The first is an online platform for crowd-sourcing affect annotations of videos, and it incorporates three different one-dimensional techniques to be used for continuous annotation of affect dimension (e.g., valence and arousal). The second tool allows the researcher to define even very complex multi-layer annotation schema, that may include emotion labels and dimensions, but also expressive behaviors (e.g., facial expressions or gestures).

\subsubsection{Context}

The other issue linked with emotion labeling is the amount of information not given by the subjects. For instance, a study might focus on two emotions: happiness and anger, and therefore the researchers within the data collection protocol may ask the participants to report only the events related to these two particular emotion labels. However, the subjects might still experience a much larger range of emotions during the data collection. At the same time, they might also perform unrelated actions such as smoking or drinking which may not be in the scope of the data collection and therefore would not be reported by the participants. These other emotions or actions, which remain unreported, may eventually corrupt the quality of the data labeling as they have an impact on the studied signal. For example coffee intake can affect Heart Rate (Green and Suls, 1996), and although progress has recently been made to reduce the effect of physical activity on emotion classification from physiological signals (Heinisch et al., 2019), still it is recommended to report such activity in self-reporting. For this reason, Schmidt et al. (2018) recommend collecting in parallel information about the physical activities and the sleep quality of the subjects and to conduct data-driven screenings interviews with the participants to gather additional context information. In their survey, Wac and Tsiourti (2014) discussed several other contextual factors (in the original paper they are called "confounding factors") that may influence the accuracy of the monitoring of the affective states. These include traits, which are constant or slowly evolving during the life, being at the same time important factors contributing to interpersonal differences, such as gender or diseases (e.g., allergies), as well as instantly changing ones, e.g., metabolic body activity related to eating, cognitive load, posture of the person. Some other contextual factors are related to the social context, e.g., being alone or in company and to the environment, such as temperature and humidity which may also influence the captured signals. In particular, social setting has a great impact on induced emotions as highlighted by Muszynski et al. (2018) who studied the synchronization of affective responses of people watching movies together.

Consequently there is a need for experimenters to request additional reports from participants about factors that are known to affect physiological signals such as alcohol, coffee or drug intake, physical activity etc. Unfortunately, this also greatly increases the complexity of the study and may affect the willingness of the participants to follow the protocol. Other solutions might need to be considered such as embedded cameras or microphones to collect the contextual data.

\subsubsection{Ambulatory Systems}

When it comes to real-life dataset collection, there is a distinction to be made between ambulatory and static studies. Collecting of real-life emotion data often requires long-term studies during which people can freely change location. This means that ambulatory systems are needed to collect physiological signals while the person is moving. Some existing studies do focus on 
real-life emotions felt by the subject, but the data collection was confined to a specific physical space, e.g., to a desk space (Roseway et al., 2015). These types of studies will be referred to as "static studies" (as opposed to ambulatory ones previously mentioned).

In ambulatory studies, several issues need to be addressed. First of all, the devices recording the data must be both mobile and comfortable as they must allow the subjects to move freely for extended periods of time. This is the main reason why real-life data collections using HR or GSR signals are more common than using, e.g., EEG. There are a few devices available commercially (July 2019) for physiological signals-based ambulatory studies which are presented in the Supplementary Materials. Some researchers chose to develop their own devices (Wilhelm et al., 2005). While it is important to choose small sensors to ensure the wearability of the device, some sensors might be more affected by movement than others. For instance, to calculate HR, it is possible to use small PPG sensors, from which the BVP is read, the InterBeat Interval (IBI) calculated and the HR extracted. This technique is reliable but very sensitive to sensor movement (Pietilä et al., 2017). An alternative approach is to use an ECG. Chest ECG, while being much more invasive, provides more precise data which are less affected by movement (Ge et al., 2016). The choice between the two is therefore a compromise between wearability and accuracy. There are also techniques that can be used to improve the accuracy of the IBI calculated from PPG (Torres et al., 2016). The most common is the use of a 3D accelerometer to detect movement (Lee et al., 2010). Furthermore, HR is also greatly affected by physical activity (e.g., sports) and it is important to remove from the physiological data the periods of such activity. Once again accelerometer may help detecting such activities with some limitation. Novel technologies might allow the heart rate to be measured for emotion recognition without the need for any on-body device through the use of RF signals reflected off the participant's body (Zhao et al., 2016).

Neuroimaging systems (e.g., functional Magnetic Resonance Imaging-fMRI-and Positron emission tomography-PET) had demonstrated their potential value in investigating affective processes (e.g., Costafreda et al., 2008, for a meta-analysis on Amygdala activation during the processing of emotional stimuli). Salimpoor et al. (2013) used fMRI to observe how pleasure as aesthetic reward can arise from the interaction between mesolimbic reward circuitry (especially the Nucleus Accumbens) and cortical networks underlying the auditory analysis and assessment. Furthermore, it was shown that even emotion reappraisal activate various brain regions such as the fronto-parietal circuit including the parietal cortex, dorsolateral prefrontal cortex, supplemental motor area and the insula (Buhle et al., 2013). These findings are in line with fMRI data showing that both the perception (i.e., observing, listening) and expressions (i.e., motor actions, speech) conveying positive or negative mood and/or affect-related attitudes (e.g., gentle vs. rude) produce the activation of the insular cortex (Di Cesare et al., 2015, 2017).

However, even if neuroimaging can be effectively applied to the study of emotional processes (e.g., Sabatinelli et al., 2017), it can be difficult or even impossible, to adopt it in the study of affective phenomena in-the-wild, since it must be used in a laboratory or similar setting with high constraints in terms of subjects' mobility. However, for some studies e.g. paralyzed patients, this setup would of course form a common daily setting. To consider physiological measures with lower spatial resolution but higher temporal resolution, electroencephalography (EEG) and functional Near Infra-Red Spectroscopy (fNIRS) can also be adopted (Balconi et al., 2015) and these techniques do allow the person to walk and move in non-laboratory settings, wearing a portable sensorized headset. To ensure the ecological validity of the data collection in the wild such systems should not be visible to other interlocutors (e.g., they can be hidden under a cap). Exceptions can come from studies in which the everyday setting can be based on watching a television program or interacting with a computer, as in neuromarketing studies (Gkaintatzis et al., 2019) or neuroergonomics studies (Watson et al., 2019) especially in experimental paradigms of BCIs (Placidi et al., 2019).

Ambulatory studies tend to collect noisy raw data that must be processed before it can be used for emotion recognition. Several layers of processing might be required such as filtering (low-pass filters, smoothing filters and so on). The topic of post-processing is out of the scope of this paper but it is covered by previous survey papers (Jerritta et al., 2011).

\subsubsection{Long-Term Experiment}

In an in-the-wild setting, it is unknown a priori how many times the subject will experience a certain emotion during the study or if he will experience it at all. However, some techniques exist to increase the likelihood of the emotion during the collection period. For instance, some subjects might know specific events in their future that are likely to trigger emotions (e.g., public presentation, important meeting, job interview). Studies involving multiple emotions might require subjects to experience a full range of emotions. This will however, greatly impact the length of the study. In that case, it is even more important to provide devices that are comfortable, so it would be acceptable for a subject to wear them over a long period of time. he possible length of the study. Indeed, the more comfortable the device, the more it would be acceptable for a subject to wear it over a long period of time.

\subsubsection{Lack of Datasets}

Considering the great inter-person variability in physiological signals of emotions, it is important to work with data of a large number of subjects. For this reason, open access datasets are very valuable for EMSR research. Unfortunately, existing open access datasets (e.g., Dan-Glauser and Scherer, 2011; Koelstra et al., 2011; Abadi et al., 2015; Sharma et al., 2018; Markova et al., 2019) contain only the data of induced emotions.

\section{THE GARAFED METHOD}

In this section, we propose a new assessment of the data collection methodologies based on their utility for building EMSR models for ambulatory real-life applications. Eight criteria were selected, each containing sub-categories. While other applications might 
have different needs and requirements (e.g., detecting stress during a written exam does not need an ambulatory setup), our assessment will be made considering exclusively any ambulatory real-life applications. In addition, even though other choices must be made when building EMSR models (such as emotion theory, see sections 2 and 3), they are not included in this assessment model. This is because such choices cannot be ranked from the most to the least suitable for real-life applications and they usually depend on the specific application.

For categories defined as intervals (e.g., between 3 and 7 days), the lower boundary (e.g., 3 days) is included in the category, and the higher number (e.g., 7 days) is not.

\subsection{The GARAFED Categories 4.1.1. Emotion Origin}

As stated in section 2, there are many possible methods to collect the emotion data. The emotion may be induced by an experimenter in the lab, or, in real-life, can be caused by other agents, events or objects (Ortony et al., 1990). By collecting data in situations similar to a natural setting, one may expect to obtain datasets which are more appropriate for EMSR for real-life applications (see our discussion in section 3.1). Here, we propose to classify existing methods into five categories:

1. Simulation of the emotion (e.g., acting).

2. Induction of emotions in-lab (e.g., movies, IAPS images).

3. Induction of emotions through supervised real-life activities (e.g., car driving, skydiving).

4. Real-life emotions, static monitoring.

5. Real-life emotions, ambulatory monitoring.

\subsubsection{Invasiveness}

The size and portability of the system used to collect data in the wild impacts how easy it is for the subjects to carry it for long periods and thus the possibility to conduct longer experiments. This invasiveness factor has been separated into four categories:

1. Non-portable: the system needs to be linked to a power supply and/or require the experimenter intervention, such as sampling of salivary cortisol level.

2. Portable and highly invasive: the system is heavy bulky or invasive. It may include sensors such as nasal respiration sensors. It is not possible to wear it for many hours a day without discomfort for the subject. (ex: Vu-ams, De Geus and Van Doornen, 1996).

3. Portable and slightly invasive: The system is light. It can be worn for several hours a day but it is noticeable and/or potentially uncomfortable for the subject after a certain time (e.g., Shimmer3 GSR+ Unit).

4. Portable and non-invasive: The system is light and does not have an impact on everyday activities, even if used over long periods. It is similar to a commonly worn object such as a watch, a belt etc.

\subsubsection{Privacy}

The input data used to classify emotions can infringe the privacy of the subject. Indeed, data such as video, voice or activities in calendar app would give the experimenter access to personal data. They may also allow for the identification of the subjects. While infringing the privacy does not influence the quality of the EMSR model, the use of such data usually is restricted or ethically unacceptable.

While this review focuses on physiological data that are less intrusive for the privacy than the data collected from other modalities, we also consider multimodal approaches (see section 5.2), which may be more intrusive. In this review we classify papers using the two categories:

1. Intrusive data: personal data or data that allows for identification.

2. Non-intrusive data: non-personal and does not allow for identification.

\subsubsection{Number of Experimental Days}

Collecting data over many days increases the probability of gathering data covering a variety of situations and contexts. This variability may improve the robustness of the model. Wac and Tsiourti (2014) emphasizes on the difficulty to collect physiological signals in the wild, and in particular, the choice of the study length, that should be a compromise between collecting representative samples and limiting the burden for the participant. We aggregated the number of days used for the dataset collection process for each paper present in this review proposing an EMSR model (see sections 5.1.1.1, 5.1.1.2, 5.2.1.1, 5.2.1.2). By extracting 4 quartiles on this data, we defined the following categories:

1. Less than 3 days.

2. Between 3 and 7 days.

3. Between 7 and 34 days.

4. 34 days or more.

For papers that give a range to the number of days in the experiment (e.g., 4-6 days), the maximum time was taken (e.g., 6 days).

\subsubsection{Number of Hours per Day}

The number of hours for data collection per day also greatly impacts the value of the dataset, and indeed, physiological signals may also vary with the time of day (Gjoreski et al., 2017). Here again we used the studies presented in this review to extract the quartiles that define the following 4 categories:

1. Less than $4 \mathrm{~h}$ per day.

2. Between 4 and $8 \mathrm{~h}$ per day.

3. Between 8 and $16 \mathrm{~h}$ per day.

4. $16 \mathrm{~h}$ a day or more.

For papers providing only a time interval per day (e.g., 12-14 h per day) the maximum time was taken (e.g., $14 \mathrm{~h}$ ).

\subsubsection{Number of Subjects}

As previously stated, high inter-personal variability is often observed in physiological signals of emotions. In order to create and validate an user-independent EMSR, it is usually recommended that the data is collected from many subjects. As 


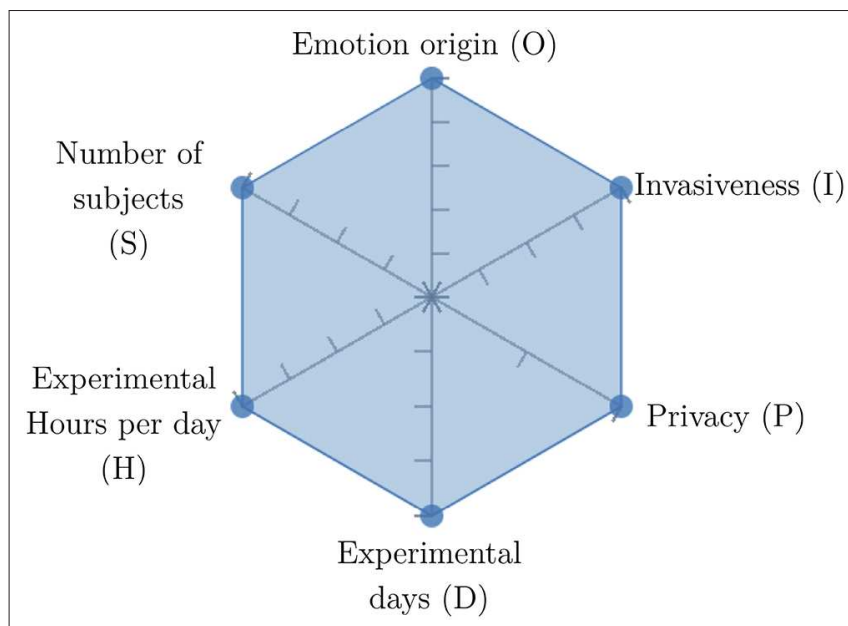

FIGURE 1 | The GARAFED method.

in the previous sections, we used the quartile method to define the following four categories:

1. Less than 6 subjects.

2. 6 to 12 subjects.

3. 12 to 24 subjects.

4. 24 subjects or more.

Quartiles were averaged to the largest round number.

These criteria represent a data collection paradigm that can be: (1) used to build, or (2) used in the selection of a dataset to build, an emotion recognition model that is usable in ambulatory reallife applications, e.g., Example 1 presented in section 1. Ideally, the data collection would be done using non-invasive and nonintrusive sensors. A study of this type should be done for an extensive time with a large number of subjects. It is worth to notice that some of criteria discussed in this section, were also postulated by other researchers (e.g., Wac and Tsiourti, 2014; see section 1.1).

\subsection{The GARAFED Visual Aid}

In order to ease the assessment of existing and future works, we propose a open visual aid: the GARAFED (Graphical Assessment of Real-life Application-Focused Emotional Dataset) method (Figure 1). Inspired by the Adapted ECOVAL framework (Labonte-LeMoyne et al., 2018), it allows for the comparison of different datasets and evaluation of their utility when applied to real-life EMSR applications.

GARAFED is open visual aid tool, in the sense it can be extended (see our discussion in section 5.3) and possible extensions may include the inclusion of the contextual data e.g., the annotation of person-related or environment-related factor (Wac and Tsiourti, 2014, see section 3.3.3). However, we understand that most features like these factors cannot be expressed by a position along an ordinal scale. they can however be listed as a set of checkboxes to define the presence or the absence of a certain factor within each data collection plan.
GARAFED can be considered a tool for the affective systems designers who need reality-based datasets for generating their own computational models to recognize certain emotional states for their own applications (Aranha et al., 2019). These models are critically important to enable artificial systems with the capability to react appropriately to the affective changes in the human experience within a specific context where the model must be initially forged through an ecologically valid data collection approach.

Some exemplary applications that can exploit GARAFEDassisted data collection to generate reality-based models of emotion recognition are listed below:

- GARAFED can assist the definition of emotion origin to design the affective system underlying a virtual reality setups for stimulating emotional states to improve mental health, relationships, well-being, empathy (Schoeller et al., 2019);

- GARAFED can show the effectiveness of a certain amount of time (days and hours per day) to collect data for implementing a wearable solution assisting daily habits meditation and physiological self-regulation through biofeedback (Choi and Ishii, 2020) to treat also psychological issues like anxiety;

- GARAFED can help to select the appropriate number of subject for developing interactive systems (e.g., games, Larradet et al., 2017) designed to be controlled by people with rare conditions like Locked-In Syndrome (LIS, a condition where severe motor impairments spares sometime only the ocular muscles, as in the late stages of Amyotrophic Lateral Sclerosis, ALS) through a relax-based biofeedback that can be enriched by explicitly emotional features monitoring;

- GARAFED can be used to implement ethically adequate choices in data collection for investigating collective emotions (Skowron et al., 2017) in online social contexts without disclosing the affective state of each participant;

- GARAFED can integrate existing approaches to design training systems for professionals that must keep their mental focus during risky operations (as in the augmented reality neurotraining for surgeons in Barresi et al., 2015) in which emotional states can be critical but a low level of invasiveness of the physiological sensors must be maintained for avoiding any invasiveness in the simulative scenario.

\section{ASSESSMENT OF EXISTING DATASETS}

In this section, we study prior works that involved experimentation in real-life or supervised real-life environments. To build this corpus of studies we used combinations of the following keywords in Google scholar: "emotion," "emotion recognition," "emotion classification," "emotion detection," "valence," "arousal," "affect," "in the wild," "in the field," "in the fray," "in real life," "ambulatory," "physiological signals," "biosignals," "heart rate," "HR," "galvanic skin response," "GSR," "electrodermal activity," "EDA," "skin Conductance," "SC," "photoplethysmogram," “PPG," "blood volume pressure," "BVP." 
Although the GARAFED may be applied to different types of input data, in this section we use it to assess papers focusing on physiological signals ${ }^{5}$. Here, we distinguish:

- Works using solely physiological signals (see section 5.1),

- Studies collecting physiological signals and additional inputs such as audio or video (see section 5.2).

In both cases, research papers will be separated into 3 categories:

- Studies which consists of collecting the data and proposing EMSR models in-the-wild.

- Empirical studies exploring physiological signals of emotions, mood or stress collected in real-life settings without proposing a detection or classification method.

- Studies which apply existing EMSR models or/and previous research results in specific real-life applications.

Only papers belonging to first category will be assessed using the GARAFED method as they provide the description of the data collection. The second category contains results that may be helpful for future model development. The third category, show EMSR real-life applications. Consequently the two last categories are a collection of relevant papers that might be useful to the reader interested in physiological data collection and EMSR.

Features extracted from the raw signals are also presented, as they are often used to improve EMSR machine learning algorithms. Common features of HR used for emotion recognition include for instance HRV, RMSSD, pNN50, or SDNN, and common features of EDA include for instance slope of the FDA. While additional signal processing such as Fourier Transforms or Wavelet transforms and feature reduction techniques such as Sequential Forward Selection (SFS) might be necessary to only select emotion related signals, they will not be presented in this review. More details on data processing, feature extraction and feature reduction can be found in Jerritta et al. (2011) and Shu et al. (2018).

A list of currently (July 2019) available devices to perform ambulatory studies is provided as a part of the Supplementary Materials.

\subsection{Physiological Signals-Based Studies \\ 5.1.1. Datasets for In-the-Wild Detection and Classification}

\subsubsection{Studies on stress}

A few studies propose methods to estimate stress in reallife settings. Plarre et al. (2011), Hovsepian et al. (2015), and Gjoreski et al. (2016) trained a model with 21 participants in the laboratory and tested it in real-life settings with 17, 20, and 5 subjects, obtaining $71 \%, 72 \%$, and $92 \%$ accuracy. Using a different approach, Dobbins et al. (2018), Muaremi et al. (2014) and Hernandez et al. (2011) used data from 6, 10, and 9 participants

\footnotetext{
${ }^{5}$ Accelerometers are widely used in combination with physiological signals, e.g., as an indicator of excessive movement and for filtering purposes. We therefore considered a study using physiological and accelerometer data as a physiological signals-only.
}

collected in-the-field to estimate stress obtaining 70\%, 73\%, and $78 \%$ accuracy respectively. Other researchers such as Healey et al. (2005) and Rigas et al. (2011) limited their works to supervised environments who aimed to detect stress in drivers obtaining respectively 97 and 82\% accuracy. Similarly, Melillo et al. (2011) used a real evaluation from a university to collect data from 42 students estimating stress with an accuracy of $95 \%$.

Lamichhane et al. (2016) monitored subjects for 5 days and addressed inter-individual differences using a Stress Response Factor in order to improve stress recognition models. Can et al. (2020) compared the machine learning models on laboratory data and on daily life data. When the models were trained the data in-the-lab, the accuracy of the system when tested in-the-wild improved significantly reaching $74 \%$ detection rate. Vila et al. (2019) estimated stress of travelers reaching an accuracy range from 92 to $100 \%$.

Table 1 summarizes the datasets used in these studies and presents their respective GARAFED.

\subsubsection{Studies on emotions and moods}

There are many fewer studies focusing on emotion or mood recognition methods tested in-the-wild. Carroll et al. (2013) studied emotional eating by detecting mood using a dimensional method. They reached 75\% recognition for arousal and $72.62 \%$ for valence. Zenonos et al. (2016) focused on recognizing moods in work environments. They proposed a model that had an accuracy of $70 \%$. Finally, Healey et al. (2010) studied emotion recognition in the wild with 19 participants and achieved an accuracy of $85 \%$ for arousal and $70 \%$ for valence. Schmidt et al. (2019) highlights the difficulties of in-the-wild emotion recognition in his field including 11 healthy subjects for 16 days. Their new methodology including multi-task CNN succeeded to reach a F1 score $1.8 \%$ higher compared to classical methods, however still relatively low (45\%). Table 2 presents those studies as well as their GARAFED representation.

\subsubsection{Empirical Studies in Real-Life Environment}

\subsubsection{Studies on stress}

Most studies on stress in the wild are preliminary. They report findings and observations of physiological reactions to natural stressors without proposing a detection model. The disparities in stress experiences in the lab compared to in the wild are assessed by Dikecligil and Mujica-Parodi (2010). They compared HRV obtained from 33 subjects during 2 short term laboratory experiments (using IAPS images), a long-term hospitalized monitoring study $(24 \mathrm{~h})$ and a supervised reallife study (180 min including a first-time tandem skydive). They found strongly predictive correlations between laboratory results and supervised real-life study. Similar supervised reallife studies were conducted, notably by Fenz and Epstein (1967), that monitored HR and respiration in 10 novice and 10 experienced parachutists during a jump. They found a sharp rise in physiological activity in novice jumpers and an inverted V-shaped curve in experienced ones. Wilhelm and Roth (1998) similarly studied HR and respiration during a plane trip with flight phobics which pointed additional $\mathrm{HR}$ as a reflection of participants anxiety. Kusserow et al. (2012b) monitored people 
TABLE 1 | Studies that collect the physiological data only and focus on stress.

\begin{tabular}{|c|c|c|c|c|c|c|c|c|c|c|}
\hline Authors & Signal & $\begin{array}{l}\text { Emotion } \\
\text { Labeling }\end{array}$ & $\begin{array}{l}\text { Testing } \\
\text { method }\end{array}$ & $\begin{array}{l}\text { Affective } \\
\text { states }\end{array}$ & $\begin{array}{l}\text { User } \\
\text { dependency }\end{array}$ & Accuracy & $\begin{array}{l}\text { Approximate } \\
\text { duration }\end{array}$ & $\begin{array}{l}\text { Number } \\
\text { of } \\
\text { subjects }\end{array}$ & $\begin{array}{l}\text { Extracted } \\
\text { physiological } \\
\text { features }\end{array}$ & Graphical representation \\
\hline \multirow[t]{2}{*}{ Plarre et al. (2011) } & \multirow[t]{2}{*}{$\begin{array}{l}\text { ECG Resp } \\
\text { Acc }\end{array}$} & $\begin{array}{l}\text { Public speaking } \\
\text { period } \\
\text { Mental arithmetic }\end{array}$ & \multirow[t]{2}{*}{$\begin{array}{l}\text { self- } \\
\text { report } \\
\text { Smartphone } \\
25 \text { EMA/day }\end{array}$} & $\begin{array}{l}\text { Psychological } \\
\text { stress }\end{array}$ & UID & $\frac{\text { Psychological }}{\frac{\text { stress: }}{90 \%}}$ & $\begin{array}{l}2 \text { days } \\
12- \\
14 \mathrm{~h} / \text { day }\end{array}$ & Lab: 21 & $\begin{array}{l}\text { ECG: RRI, } \\
\text { LF, MF, HF, } \\
\text { LF/HF }\end{array}$ & 1 \\
\hline & & $\begin{array}{l}\text { Cold pressor } \\
\text { Self-report }\end{array}$ & & $\begin{array}{l}\text { Perceived } \\
\text { stress }\end{array}$ & & \multicolumn{2}{|l|}{$\begin{array}{l}\text { Perceived stress: } \\
\text { lab :72\% } \\
\text { field: } 71 \%\end{array}$} & Field: 17 & $\begin{array}{l}\frac{\text { Respiration: }}{\mathrm{ID}, \mathrm{ED}, \mathrm{RD},} \\
\mathrm{IE} \text { ratio, stretch, } \\
\text { min Ve/min Vo, } \\
\text { RSA }\end{array}$ & D \\
\hline Hovsepian et al. (2015) & $\begin{array}{l}\text { ECG Resp } \\
\text { Acc }\end{array}$ & $\begin{array}{l}\text { Public speaking } \\
\text { period } \\
\text { Mental arithmetic } \\
\text { Cold pressor } \\
\text { Self-report }\end{array}$ & $\begin{array}{l}\text { Self- } \\
\text { report } \\
\text { Smartphone } \\
15 \\
\text { EMA/day }\end{array}$ & Stress & UID & $\begin{array}{l}\text { lab:89\% } \\
\text { field: } 72 \%\end{array}$ & $\begin{array}{l}7 \text { days } 10- \\
16 \text { h/day }\end{array}$ & $\begin{array}{l}\text { Lab: } 26 \\
\text { Field: } 20\end{array}$ & $\begin{array}{l}\text { ECG: RRI, HRV, } \\
\text { LF, MF, HF, } \\
\text { LF/HF, HR } \\
\text { Respiration: } \\
\text { ID, ED, RD, } \\
\text { IE ratio, stretch, } \\
\text { RSA }\end{array}$ & D \\
\hline Healey et al. (2005) & $\begin{array}{l}\text { ECG EMG } \\
\text { EDA Resp }\end{array}$ & $\begin{array}{l}\text { Driving (rest, } \\
\text { highway, city) } \\
\text { Validated by: } \\
\text { Self-report Score } \\
\text { derived from video }\end{array}$ & $\begin{array}{l}\text { Leave- } \\
\text { one- } \\
\text { out }\end{array}$ & Stress & UD & $97.40 \%$ & $\begin{array}{l}\text { 1-7 days } \\
2 \mathrm{~h} / \text { day }\end{array}$ & 9 & $\begin{array}{l}\text { EKG: } \\
\text { HR, RRI, HRV }\end{array}$ & $\mathrm{H}^{2}$ \\
\hline Rigas et al. (2011) & $\begin{array}{l}\text { ECG EDA } \\
\text { Resp }\end{array}$ & $\begin{array}{l}\text { Driving } \\
\text { Self-report } \\
\text { voluntary oral }\end{array}$ & $\begin{array}{l}\text { Leave- } \\
\text { one-out }\end{array}$ & Stress & UID & $82 \%$ & $\begin{array}{l}\sim 40 \text { days } \\
50 \text { min } \\
/ \text { day }\end{array}$ & 13 & $\begin{array}{l}\text { ECG: RRV, HRV } \\
\text { EDA: SCL, SCR, } \\
\text { FAD, normalized } \\
\text { measure of the } \\
\text { differences } \\
\text { Respiration: } \\
\text { spectral entropy }\end{array}$ & D \\
\hline
\end{tabular}


TABLE 1 | Continued

\begin{tabular}{|c|c|c|c|c|c|c|c|c|c|c|}
\hline Authors & Signal & $\begin{array}{l}\text { Emotion } \\
\text { Labeling }\end{array}$ & $\begin{array}{l}\text { Testing } \\
\text { method }\end{array}$ & $\begin{array}{l}\text { Affective } \\
\text { states }\end{array}$ & $\begin{array}{l}\text { User } \\
\text { dependency }\end{array}$ & Accuracy & $\begin{array}{l}\text { Approximate } \\
\text { duration }\end{array}$ & $\begin{array}{l}\text { Number } \\
\text { of } \\
\text { subjects }\end{array}$ & $\begin{array}{l}\text { Extracted } \\
\text { physiological } \\
\text { features }\end{array}$ & Graphical representation \\
\hline Dobbins et al. (2018) & PPG GSR & $\begin{array}{l}\text { Self-report } \\
\text { Smartphone 2/day }\end{array}$ & $\begin{array}{l}\text { Leave- } \\
\text { one-out }\end{array}$ & Stress & UID & $70 \%$ & $\begin{array}{l}10 \text { days } \\
\text { Waking } \\
\text { hours }\end{array}$ & 6 & - & $\mathrm{s}$ \\
\hline Gjoreski et al. (2016) & $\begin{array}{l}\text { PPG GSR } \\
\text { ST Acc }\end{array}$ & Mental arithmetic & $\begin{array}{l}\text { Self-report } \\
\text { Smartphone } \\
4-6 \\
\text { EMA/day }\end{array}$ & Stress & UID & $92 \%$ & 55 days & $\begin{array}{l}\text { Lab: } 21 \\
\text { Field: } 5\end{array}$ & $\begin{array}{l}\text { PPG: HR, HRV, } \\
\text { RMSSD, SDNN, } \\
\text { RRI, LF, HF, MF, } \\
2 \text { LF/HF, } \\
\text { pNN2O-50-70 } \\
\text { GSR \& HR \& ST: } \\
\text { slope, intercept } \\
\text { of signal GSR: } \\
\text { Peaks, } \\
\text { significant peaks }\end{array}$ & $\mathrm{S}$ \\
\hline Muaremi et al. (2014) & $\begin{array}{l}\text { ECG Resp } \\
\text { ST GSR } \\
\text { Acc }\end{array}$ & Self-report 1 / day & $\begin{array}{l}\text { Leave- } \\
\text { one-out }\end{array}$ & Stress & UID & $73 \%$ & $\begin{array}{l}18 \text { nights } \\
\sim 6 h 30 / \text { night }\end{array}$ & 10 & $\begin{array}{l}\text { ECG: } \\
\text { HRV, LF/HF, } \\
\text { SD1/SD2 ST: } \\
\text { Peaks }\end{array}$ & s \\
\hline Hernandez et al. (2011) & EDA & Self-report 1 / call & $\begin{array}{l}\text { Leave- } \\
\text { one-out }\end{array}$ & Stress & Both & $\begin{array}{l}\text { UD :78.03\% } \\
\text { UID: } \\
73.4 \%\end{array}$ & $\begin{array}{l}7 \text { days } \\
\text { work hours }\end{array}$ & 9 & - & \\
\hline Melillo et al. (2011) & ECG & $\begin{array}{l}\text { Stressor: } \\
\text { University } \\
\text { evaluation } \\
\text { Control: After } \\
\text { holidays }\end{array}$ & $\begin{array}{l}\text { Leave- } \\
\text { one-out }\end{array}$ & Stress & UID & $95 \%$ & $\begin{array}{l}2 \text { days } \\
5 \mathrm{~m} / \text { day }\end{array}$ & 42 & $\begin{array}{l}\text { ECG: HRV, RRI, } \\
\text { SDNN, ApEn }\end{array}$ & \\
\hline
\end{tabular}


TABLE 1 | Continued

\begin{tabular}{|c|c|c|c|c|c|c|c|c|c|c|}
\hline Authors & Signal & $\begin{array}{l}\text { Emotion } \\
\text { Labeling }\end{array}$ & $\begin{array}{l}\text { Testing } \\
\text { method }\end{array}$ & $\begin{array}{l}\text { Affective } \\
\text { states }\end{array}$ & $\begin{array}{l}\text { User } \\
\text { dependency }\end{array}$ & Accuracy & $\begin{array}{l}\text { Approximate } \\
\text { duration }\end{array}$ & $\begin{array}{l}\text { Number } \\
\text { of } \\
\text { subjects }\end{array}$ & $\begin{array}{l}\text { Extracted } \\
\text { physiological } \\
\text { features }\end{array}$ & Graphical representation \\
\hline Lamichhane et al. (2016) & $\begin{array}{l}\text { ECG 3D } \\
\text { Acc Resp } \\
\text { GSR }\end{array}$ & $\begin{array}{l}\text { self-report } \\
\text { Smartphone EMA } \\
\text { every } 30 \text { min }\end{array}$ & $\begin{array}{l}\text { Leave- } \\
\text { one-out }\end{array}$ & $\begin{array}{l}\text { Perceived } \\
\text { Stress }\end{array}$ & UID & $\begin{array}{l}\text { Average } \\
\text { mean } \\
\text { squared } \\
\text { error by up } \\
\text { to } 32 \%\end{array}$ & $\begin{array}{l}5 \text { days } \\
\text { work hours }\end{array}$ & 10 & $\begin{array}{l}\text { ECG: RRI, HR, } \\
\text { rmssd, LF, HR, } \\
\text { LF/HF, pnn50, } \\
\text { apen, sd1, sd2, } \\
\text { sd1/sd2 GSR: } \\
\text { scl, scp, scrr, } \\
\text { scdiff2 } \\
\text { Respiration: } \\
\text { RR, cycles/m }\end{array}$ & ${ }_{H}^{S}$ \\
\hline & & & & & & & & & & D \\
\hline Can et al. (2020) & $\begin{array}{l}\text { PPG GSR } \\
\text { ST 3D Acc }\end{array}$ & $\begin{array}{l}\text { Public speaking } \\
\text { period }\end{array}$ & $\begin{array}{l}\text { self-report } \\
\text { Smartphone } \\
1 \text { EMA } \\
\text { every 3h }\end{array}$ & stress & UID & $73.8 \%$ & 7 days $12 \mathrm{~h}$ & 14 & $\begin{array}{l}\text { EDA: Peaks } \\
\text { Strong peaks } \\
\text { PPG: HRV, RRI, } \\
\text { SDNN, RMSSD, } \\
\text { Pnn5O, TINN, LF, } \\
\text { HF, LF/HF, HRV } \\
\text { triangular index }\end{array}$ & $S$ \\
\hline Vila et al. (2019) & $\begin{array}{l}\text { PPG GSR } \\
\text { ST 3D Acc }\end{array}$ & self-report & $\begin{array}{l}\text { Leave- } \\
\text { one-out }\end{array}$ & stress & UD & $\begin{array}{l}92.6 \%- \\
100 \%\end{array}$ & $\begin{array}{l}3 \text { days } \\
\text { Waking } \\
\text { hours }\end{array}$ & 1 & $\begin{array}{l}\text { EDA: SCL, SCR } \\
\text { Local minima } \\
\text { PPG: } \\
\text { IBI, RMSSSD, } \\
\text { HR, LF, HF, } \\
\text { LF/HF }\end{array}$ & $s$ \\
\hline
\end{tabular}


TABLE 2 | Studies that collect the physiological data only and focus on emotions and moods.

\begin{tabular}{|c|c|c|c|c|c|c|c|c|c|c|}
\hline Authors & Signal & Emotion labeling & $\begin{array}{l}\text { Testing } \\
\text { method }\end{array}$ & $\begin{array}{l}\text { Affective } \\
\text { states }\end{array}$ & $\begin{array}{l}\text { User } \\
\text { dependency }\end{array}$ & Accuracy & $\begin{array}{l}\text { Approximate } \\
\text { duration }\end{array}$ & $\begin{array}{l}\text { Number } \\
\text { of } \\
\text { subjects }\end{array}$ & $\begin{array}{l}\text { Extracted } \\
\text { physiological } \\
\text { features }\end{array}$ & Graphical representation \\
\hline Healey et al. (2010) & $\begin{array}{l}\text { GSR ECG } \\
\text { AcC }\end{array}$ & $\begin{array}{l}\text { Self-report } \\
\text { Voluntary } \\
\text { Smartphone 2D } \\
\text { map }\end{array}$ & $\begin{array}{l}\text { Self-report } \\
\text { Smartphone }\end{array}$ & $\begin{array}{l}\text { Valence- } \\
\text { Arousal }\end{array}$ & UID & $\begin{array}{l}85 \% \\
\text { Arousal } \\
70 \% \\
\text { Valence }\end{array}$ & $\begin{array}{l}5 \text { days } 8+ \\
\text { h/day }\end{array}$ & 19 & $\begin{array}{l}\text { ECG: HR, HRV, } \\
\text { RMSSD GSR; } \\
\text { slope, kurtosis, } \\
\text { Peak frequency, } \\
\text { rise/falls times }\end{array}$ & $\mathrm{s}$ \\
\hline Carroll et al. (2013) & $\begin{array}{l}\text { Resp EKG } \\
\text { EDA Acc }\end{array}$ & $\begin{array}{l}\text { Self-report } \\
\text { Smartphone } 1 \\
\text { EMA/h 2D map }\end{array}$ & $\begin{array}{l}\text { Leave- } \\
\text { one-out }\end{array}$ & $\begin{array}{l}\text { Valence- } \\
\text { Arousal }\end{array}$ & UID & $\begin{array}{l}\text { Arousal : } \\
75 \% \\
\text { Valence : } \\
72.62 \%\end{array}$ & $\begin{array}{l}4 \text { days } 4-6 \\
\text { h/day }\end{array}$ & 4 & EKG: HR & $\mathrm{S}$ \\
\hline Zenonos et al. (2016) & $\begin{array}{l}\text { ECG PPG } \\
\text { ST AcC }\end{array}$ & $\begin{array}{l}\text { Self-report } \\
\text { Smartphone } 1 \\
\text { EMA/2h Emotions }\end{array}$ & $\begin{array}{l}\text { Leave- } \\
\text { one-out }\end{array}$ & $\begin{array}{l}\text { Excited } \\
\text { Happy } \\
\text { Calm } \\
\text { Tired } \\
\text { Bored } \\
\text { Sad } \\
\text { Depressed } \\
\text { Angry }\end{array}$ & Both & $\begin{array}{l}\text { Average : } \\
\text { UD: } 70 \% \\
\text { UID : } 62 \%\end{array}$ & $\begin{array}{l}5 \text { days } \\
8 \text { h/day }\end{array}$ & 4 & $\begin{array}{l}\text { EKG: IBI, SDNN, } \\
\text { RMSSD, } \\
\text { pNN50, HRVi, } \\
\text { TINN, PWTT, } \\
\text { PSD, LF, HF, } \\
\text { LF/HF }\end{array}$ & $\mathrm{H}^{2}$ \\
\hline Schmidt et al. (2019) & $\begin{array}{l}\text { ECG PPG } \\
\text { ST AcC }\end{array}$ & $\begin{array}{l}\text { Self-report } \\
\text { Smartphone } 1 \\
\text { EMA/2h \& } \\
\text { Voluntary }\end{array}$ & $\begin{array}{l}\text { Leave- } \\
\text { one-out }\end{array}$ & $\begin{array}{l}\text { Valence \& } \\
\text { arousal } \\
\text { State-Trait } \\
\text { Anxiety } \\
\text { Inventory } \\
\text { Stress }\end{array}$ & Both & $\begin{array}{l}\text { UID } \\
\text { F1scores: } \\
31 \%-47 \%\end{array}$ & $\begin{array}{l}16 \text { days } \\
15 \text { h/day }\end{array}$ & 11 & $\begin{array}{l}\text { PPG: HR, HRV, } \\
\text { EDA: Peaks }\end{array}$ & $H^{2}$ \\
\hline
\end{tabular}


in the wild as well as a musician, an Olympic ski jumper, and a public speaker. They found correlations between HR and stress. Baek et al. (2009) evaluated stress in driving using a custom car equipped with sensors (ECG, GSR, Resp). In this supervised reallife study, temperature, noise, time of day (night vs. daytime) and simultaneous arithmetic calculations separated were altered to create stressful environments. They found meaningful changes in physiological signals in simulated stressful environment. Different physiological reactions in participants were obtained for the same stressor. This highlights individual differences in reaction to emotional triggers.

Ambulatory in-the-wild studies were also conducted. Verkuil et al. (2016) proposed an in-the-lab calibration using rest, standing, cycling and stair climbing to improve the capabilities of categorizing metabolic and non-metabolic HRV reductions in-the-wild (24 h) using ECG and 3D accelerometer. HRV was found associated with negative affect and worrying. Johnston and Anastasiades (1990) studied the relation between HR and stress, arousal and time pressure in real life over a period of 24 $\mathrm{h}$ with 32 subjects. No significant relations were found between the HR and the emotional state in most participants. A significant relationship was obtained only in a small subset of subjects who were found to be more anxious, angry and with higher systolic blood pressure.

\subsubsection{Studies on emotions and moods}

Studies on mood and emotions are less common than those focusing on stress. Myrtek and Brügner (1996) studied ECG associated with an accelometer to compare the data of laboratory induced emotional events to real life experiences. The selfreports of 500 participants during a $23 \mathrm{~h}$ ambulatory study were used and highlighted disparities between emotional arousal inthe-wild compared to results obtained in laboratory. Kusserow et al. (2012a) proposed an improvement to the additional heart rate method to determine arousal by improving the physical activity detection. They used this technique to assess arousal during daily activities such as taking public transport or office work. Picard and Rosalind (2000) proposed innovative ways to gather physiological signals for ambulatory emotion recognition, notably EDA sensors in earrings, shoes and glasses. Schmidt et al. (2018) collected 1081 EMAs from 10 subjects over 148 days.

\subsubsection{Real-Life Applications}

\subsubsection{Studies on stress}

While no gold standard in terms of stress detection in-the-wild exists, some studies have used the previously presented findings to assess stress levels for further purposes. For instance, Massot et al. (2011) used physiological signals to evaluate the stressful part of a walking path for blind test subjects, while Al-Fudail and Mellar (2008) used GSR to evaluate teachers' stress levels when using technological tools in the classroom. Similarly, Wettstein et al. (2020) studies teachers' stress using cortisol levels, HR, and HRV highlighting significant differences between free days and working days.

Myrtek et al. (1999) studied 29 blue and 57 white collar workers to determine stress and strain at work using HR. Several indices were used to define each type of strain: HR for total strain, physical activity for physical strain, and HRV for mental strain. Later, Myrtek et al. (2005) took the same approach to evaluate stress and strain in female students. They found that there are two type of persons "cool" (no emotion perception) and "emotional" (high emotion perception). Kimhy et al. (2009) evaluated the relation between stress and arousal for 20 patients with psychosis using both EMAs and the Life Shirt (Grossman, 2004) during $36 \mathrm{~h}$ ambulatory studies. Zhang et al. (2012), designed a mobile application that estimates stress using HRV and prompted the user to relax using breathing exercises. Rahman et al. (2014) studied stress in illicit drug users, daily smokers and drinkers. They used the previously mentioned model of Plarre et al. (2011) to assess stress and found after the first week a significant learning effect from the subjects in how to provide valuable data. Karlsson et al. (2011) studied the reaction of ambulance professionals to alarms. They showed that all subjects experienced increased heart rate when there was an alarm regardless of their experience, education, and gender, which implies the physical arousal is detected by the heart rate.

\subsubsection{Studies on emotions and moods}

Existing models were often applied in real-life applications and experiments. For instance, Kim and Fesenmaier (2015) used EDA to estimate 2 travelers' emotions during a 4 days trip. Their mean EDA level seemed to correlate with their experience of each activity. Roseway et al. (2015) used EDA to determine arousal and HRV to determine valence in 10 participants during a 10 day study. Arousal was displayed using a color-changing emotional crystal to help mood-awareness during work in the workplace. The device seemed to improve stress control abilities in the subjects. Similarly, Snyder et al. (2015) used the color of a desk lamp to reflect subjects internal state estimated from EDA.

\subsection{Multimodal Approaches}

Collecting additional signals (e.g., audio) in addition to physiological signals might ease the recognition of emotions, moods and stress. In this section, we will present studies using a multimodal approach (physiological signals included).

\subsubsection{In-the-Wild Detection and Classification Studies}

\subsubsection{Studies on stress}

A few studies have used physiological signals combined with additional inputs to study stress. For instance, Muaremi et al. (2013) used smartphone information such as phone calls and calendar associated with heart rate to detect stress. They achieved a $61 \%$ accuracy. Rigas et al. (2011) associated driving event information with physiological signals to detect drivers' stress levels and obtained an accuracy of $96 \%$. The summary of these studies and the assessment of their datasets may be found in Table 3.

\subsubsection{Studies on emotions and moods}

Moods and emotions have also been studied using multimodal inputs. Kanjo et al. (2018) associated noise environment, ambient light levels and air pressure to physiological signals to 
TABLE 3 | Studies that collect the multimodal data and focus on stress.

\begin{tabular}{|c|c|c|c|c|c|c|c|c|c|c|}
\hline Authors & Data & $\begin{array}{l}\text { Emotion } \\
\text { Labeling }\end{array}$ & $\begin{array}{l}\text { Testing } \\
\text { method }\end{array}$ & $\begin{array}{l}\text { Affective } \\
\text { states }\end{array}$ & $\begin{array}{l}\text { User } \\
\text { dependency }\end{array}$ & Accuracy & $\begin{array}{l}\text { Approximate } \\
\text { duration }\end{array}$ & $\begin{array}{l}\text { Number } \\
\text { of } \\
\text { subjects }\end{array}$ & $\begin{array}{l}\text { Extracted } \\
\text { physiological } \\
\text { features }\end{array}$ & Graphical representation \\
\hline Muaremi et al. (2013) & $\begin{array}{l}\text { Microphone } \\
\text { Acc GPS } \\
\text { Phone } \\
\text { calls } \\
\text { Address } \\
\text { book } \\
\text { Calendar } \\
\text { Battery } \\
\text { ECG }\end{array}$ & $\begin{array}{l}\text { Self-report } \\
\text { Smartphone Audio } \\
4 \text { EMA /day }\end{array}$ & $\begin{array}{l}\text { Leave- } \\
\text { one-out }\end{array}$ & Stress & UD & $61 \%$ & $\begin{array}{l}4 \text { months } \\
12- \\
14 \mathrm{~h} / \text { day }\end{array}$ & 35 & $\begin{array}{l}\text { ECG: } \\
\text { RR, SDNN, } \\
\text { RMSSD, } \\
\text { pNN50, HRVi, } \\
\text { TINN, ApEn, } \\
\text { SD1, } \\
\text { SD2, SD1/SD2, } \\
\text { LF, HF, LF/HF }\end{array}$ & $\mathrm{S}$ \\
\hline Rigas et al. (2011) & $\begin{array}{l}\text { ECG EDA } \\
\text { Resp } \\
\text { Driving } \\
\text { event }\end{array}$ & $\begin{array}{l}\text { Driving } \\
\text { Self-report } \\
\text { voluntary Oral }\end{array}$ & $\begin{array}{l}\text { Leave- } \\
\text { one-out }\end{array}$ & Stress & UID & $96 \%$ & $\begin{array}{l}\sim 40 \text { days } \\
50 \mathrm{~min} / \text { day }\end{array}$ & 13 & $\begin{array}{l}\text { ECG: RRV, HRV, } \\
\text { RRI EDA: SCL, } \\
\text { SCR, FAD } \\
\text { Respiration } \\
\text { Spectrum } \\
\text { energy } \\
\text { Spectrum } \\
\text { entropy }\end{array}$ & $\mathrm{S}<$ \\
\hline Gjoreski et al. (2017) & $\begin{array}{l}\text { PPG EDA } \\
\text { ST Acc } \\
\text { Activity } \\
\text { Hour of } \\
\text { the day } \\
\text { Type of day }\end{array}$ & $\begin{array}{l}\text { Self-report } \\
\text { Smartphone 4-6 } \\
\text { EMA \& Voluntary }\end{array}$ & $\begin{array}{l}\text { Leave- } \\
\text { one-out }\end{array}$ & Stress & UID & $\begin{array}{l}\text { Recall } \\
: 70 \% \\
\text { Precision : } \\
95 \%\end{array}$ & 55 days & 5 & $\begin{array}{l}\text { PPG: BV, HR, } \\
\text { RMSSD, slope, } \\
\text { power } \\
\text { spectrum, LF,MF, } \\
\text { HF, LF/HF, } \\
\text { RMSSD, } \\
\text { pNN20-50-70 }\end{array}$ & $\mathrm{S}$ \\
\hline
\end{tabular}


TABLE 4 | Studies that collect the multimodal data and focus on emotions and moods.

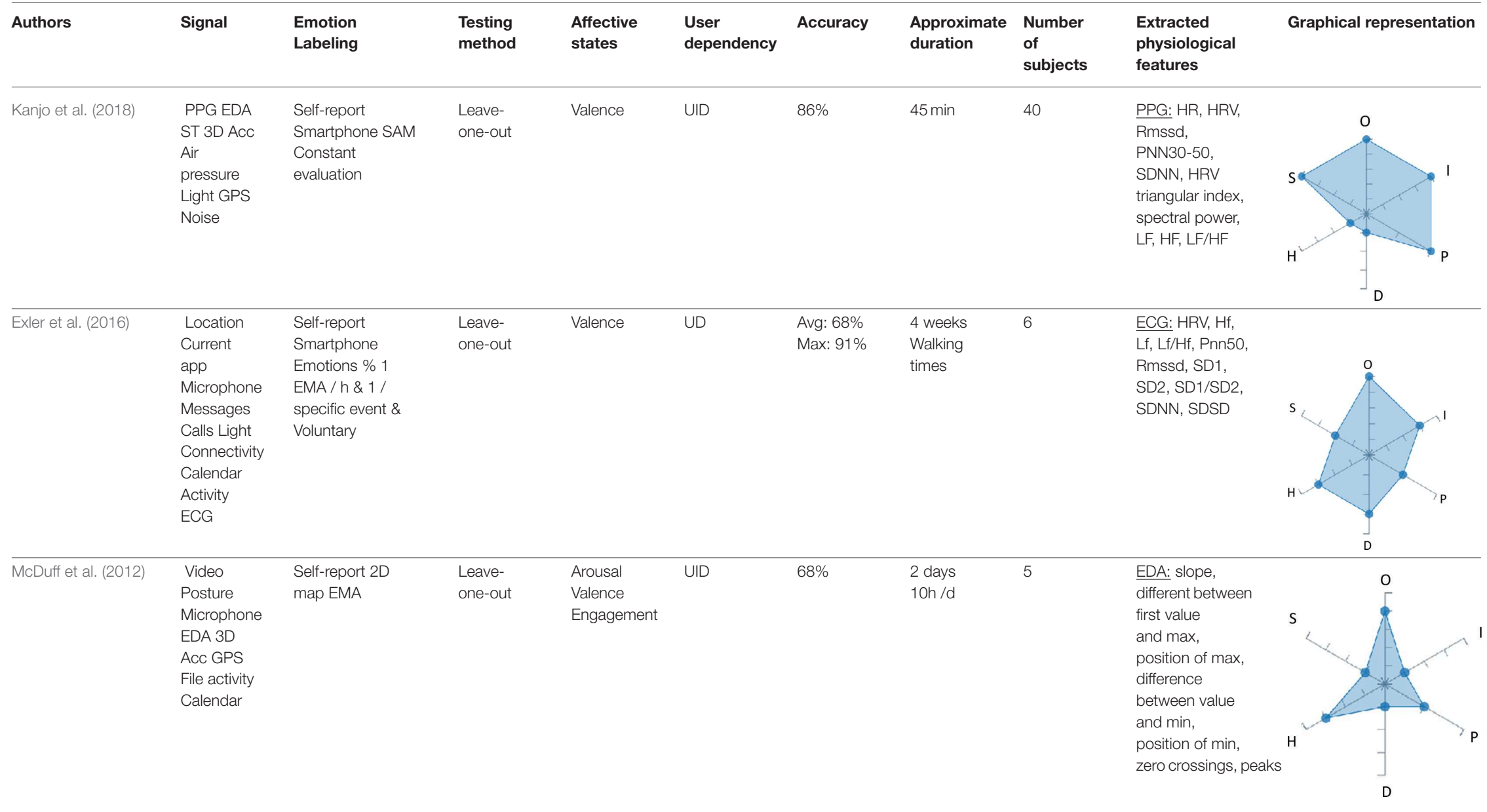


predict emotions with a $86 \%$ accuracy. Exler et al. (2016) used smartphone extracted data, such as calls and calendar associated with $\mathrm{HR}$, to evaluate valence with a $91 \%$ accuracy. McDuff et al. (2012) limited their study to a work desk, adding devices such as cameras and position sensors. Their valence, arousal and engagement recognition model reached an overall accuracy of $68 \%$. Those studies are presented in Table 4 alongside with their GARAFED assessment.

\subsubsection{Empirical Studies in Real-Life Environment} Pärkkä et al. (2008) studied the relationship between physiological signals, behavioral variables, exterior variables such as temperature, room illumination and self-reports of moods, and stress for 3 months with 17 subjects. Sarker et al. (2016) analyzed the GPS, activity and physiological data of 38 subjects during a 4 weeks experiment. They focused on the predictability of stress events duration and likelihood of stress events at different times of the day. They proposed a way of predicting the likelihood of a momentary stress episode esculating to become significant. Adams et al. (2014) collected EDA, microphone input and stress self-reports of 7 participants for 10 days. They found a correlation between audio profiles, EDA and self-reports of stress. Kocielnik et al. (2013) used GSR to evaluate arousal during a workday. The system created a 5-level arousal map (very high arousal to very low arousal) associated with calendar activities. 91\% of the users found the generated arousal map a good reflection of their feelings.

\subsection{Limitations}

Whilst this method provides an intuitive tool for easy comparison of existing affect-related data collections in-the-wild, which can be understood even by non-experts, it does have some limitations. First, in this paper we have stressed that the context of the data collection is important, especially in the case of physiological data (see section 3.3.3). However, the GARAFED method does not introduce criteria to measure contextual information. Trying to add a metric to assess context would make the visual aid much more complex, as we are not aware of any method that could allow encoding the variety of contexts in a form of one additional dimension. The simple distinction between the "known-context" vs. "unknown-context" might not be enough. Future work in this topic should focus on appropriate classification of the variety of contexts under which the data collection is performed. The other factor that might influence the dataset assessment is the source of ground-truth (i.e., mainly through self-reporting methods). However it cannot be expressed by a position along an ordinal scale as there is no consensus which self-reporting method is the most appropriate one.

Another limitation of the GARAFED method regards the definition of the categories for criteria 4-6, which are based on the data provided from currently available datasets. If long- term physiological data collection becomes more popular, the proposed ranges might need to be updated.

\section{DISCUSSION}

Accurate emotion recognition in-the-wild has a great potential to support affective science research and to develop applications designed for the general public. Whether it is applied to robotics (with robotics understanding of human emotions), to healthcare technologies (for monitoring the patients' affective state), to domotics (for adapting the home setting to the individual mood), emotion recognition has been a goal of the scientific community for decades. However, research has mainly been limited to laboratories and needs to be broadened to the wild to truly achieve meaningful progress. In this review we presented the main differences between classification and detection of emotions according to data collection in-the-wild and in the laboratory. We highlighted the main decisions to be taken, according to the goal of the desired study, their advantages, challenges and limitations, and we proposed a visual method-GARAFED - to categorize studies based on those main choices. Studies, past or future, using physiological signals or other types of input for emotion, stress or mood recognition may be assessed using this method. We presented the reason why there is a real need for research to be done in emotions recognition in-the-wild and showed that, while there has been some research in this area, there are still very few papers focus on this matter today. The quantified-self trend associated with the smaller and more portable sensor technology does, however, now make it easier for researcher to follow this path.

\section{AUTHOR CONTRIBUTIONS}

FL wrote the initial draft of the manuscript and defined GARAFED. RN contributed mainly to sections 1.1 and 2. GB contributed to the texts on ecological validity and neuroscientific methods, to the GARAFED representation of time and section 4.2. FL, RN, GB, DC, and LM contributed to manuscript writing, revision, read and approved the submitted version.

\section{FUNDING}

This work was partially supported by Fondazione Roma as part of the project TEEP-SLA.

\section{SUPPLEMENTARY MATERIAL}

The Supplementary Material for this article can be found online at: https://www.frontiersin.org/articles/10.3389/fpsyg. 2020.01111/full\#supplementary-material 


\section{REFERENCES}

Abadi, M. K., Subramanian, R., Kia, S. M., Avesani, P., Patras, I., and Sebe, N. (2015). DECAF: MEG-based multimodal database for decoding affective physiological responses. IEEE Trans. Affect. Comput. 6, 209-222. doi: 10.1109/TAFFC.2015.2392932

Adams, P., Rabbi, M., Rahman, T., Matthews, M., Voida, A., Gay, G., et al. (2014). "Towards personal stress informatics: comparing minimally invasive techniques for measuring daily stress in the wild," in Proceedings of the 8th International Conference on Pervasive Computing Technologies for Healthcare (Oldenburg: ICST), 72-79. doi: 10.4108/icst.pervasivehealth.2014.254959

Al-Fudail, M., and Mellar, H. (2008). Investigating teacher stress when using technology. Comput. Educ. 51, 1103-1110. doi: 10.1016/j.compedu.2007.11.004

Aljanaki, A., Yang, Y.-H., and Soleymani, M. (2017). Developing a benchmark for emotional analysis of music. PLOS ONE 12:e173392. doi: 10.1371/journal.pone.0173392

AlZoubi, O., D’Mello, S. K., and Calvo, R. A. (2012). Detecting naturalistic expressions of nonbasic affect using physiological signals. IEEE Trans. Affect. Comput. 3, 298-310. doi: 10.1109/T-AFFC.2012.4

Amodio, D. M., Zinner, L. R., and Harmon-Jones, E. (2007). "Social psychological methods of emotion elicitation," in Handbook of Emotion Elicitation and Assessment, eds J. A. Coan and J. J. B. Allen (New York, NY: Oxford University Press), 91-105.

Aranha, R. V., Corrêa, C. G., and Nunes, F. L. (2019). Adapting software with affective computing: a systematic review. IEEE Trans. Affect. Comput. 1. doi: 10.1109/TAFFC.2019.2902379

Baek, H. J., Lee, H. B., Kim, J. S., Choi, J. M., Kim, K. K., and Park, K. S. (2009). Nonintrusive biological signal monitoring in a car to evaluate a driver's stress and health state. Telemed. eHealth 15, 182-189. doi: 10.1089/tmj.2008.0090

Balconi, M., Grippa, E., and Vanutelli, M. E. (2015). What hemodynamic (fNIRS), electrophysiological (EEG) and autonomic integrated measures can tell us about emotional processing. Brain Cogn. 95, 67-76. doi: 10.1016/j.bandc.2015.02.001

Barresi, G., Olivieri, E., Caldwell, D. G., and Mattos, L. S. (2015). "Braincontrolled AR feedback design for user's training in surgical HRI," in 2015 IEEE International Conference on Systems, Man, and Cybernetics (Kowloon Tong: IEEE), 1116-1121. doi: 10.1109/SMC.2015.200

Bassano, C., Ballestin, G., Ceccaldi, E., Larradet, F., Mancini, M., Volta, E., et al. (2019). A VR Game-based System for Multimodal Emotion Data Collection, 12th annual ACM SIGGRAPH conference on Motion, Interaction and Games 2019 (MIG 2019) (Newcastle Upon Tyne). doi: 10.1145/3359566.3364695

Baveye, Y., Dellandréa, E., Chamaret, C., and Chen, L. (2015). "Deep learning vs. Kernel methods: performance for emotion prediction in videos," in 2015 International Conference on Affective Computing and Intelligent Interaction (ACII) (Xian: IEEE), 77-83. doi: 10.1109/ACII.2015.7344554

Bradley, M. M., and Lang, P. J. (1994). Measuring emotion: the self-assessment manikin and the semantic differential. J. Behav. Therapy Exp. Psychiatry 25, 49-59. doi: 10.1016/0005-7916(94)90063-9

Britton, B. K., Richardson, D., Smith, S. S., and Hamilton, T. (1983). Ethical aspects of participating in psychology experiments: effects of anonymity on evaluation, and complaints of distressed subjects. Teach. Psychol. 10, 146-149. doi: 10.1207/s15328023top1003_6

Buhle, J. T., Silvers, J. A., Wager, T. D., Lopez, R., Onyemekwu, C., Kober, H., et al. (2013). Cognitive reappraisal of emotion: a meta-analysis of human neuroimaging studies. Cereb. Cortex 24, 2981-2990. doi: 10.1093/cercor/ bht154

Can, Y. S., Gokay, D., Kılıç, D. R., Ekiz, D., Chalabianloo, N., and Ersoy, C. (2020). How laboratory experiments can be exploited for monitoring stress in the wild: a bridge between laboratory and daily life. Sensors 20:838. doi: 10.3390/s20030838

Carroll, E. A., Czerwinski, M., Roseway, A., Kapoor, A., Johns, P., Rowan, K., et al. (2013). "Food and mood: just-in-time support for emotional eating," in 2013 Humaine Association Conference on Affective Computing and Intelligent Interaction (Geneva: IEEE), 252-257. doi: 10.1109/ACII.2013.48

Choi, K. Y., and Ishii, H. (2020). "ambienBeat: Wrist-worn mobile tactile biofeedback for heart rate rhythmic regulation," in Proceedings of the Fourteenth International Conference on Tangible, Embedded, and Embodied Interaction (Sydney, NSW), 17-30. doi: 10.1145/3374920.3374938
Clore, G.L., Gasper, K., and Garvin, E. (2001). “Affect as information,” in Handbook of Affect and Social Cognition, ed J. P. Forgas (Mahwah, NJ: Erlbaum), 121-144. Cole, T. (1995). Acting: A Handbook of the Stanislavski Method. Three Rivers Press. Constantine, L., and Hajj, H. (2012). "A survey of ground-truth in emotion data annotation," in 2012 IEEE International Conference on Pervasive Computing and Communications Workshops (Lugano: IEEE), 697-702. doi: 10.1109/PerComW.2012.6197603

Costafreda, S. G., Brammer, M. J., David, A. S., and Fu, C. H. (2008). Predictors of amygdala activation during the processing of emotional stimuli: a meta-analysis of 385 PET and fMRI studies. Brain Res. Rev. 58, 57-70. doi: 10.1016/j.brainresrev.2007.10.012

Dan-Glauser, E. S., and Scherer, K. R. (2011). The Geneva affective picture database (gaped): a new 730-picture database focusing on valence and normative significance. Behav. Res. Methods 43:468. doi: 10.3758/s13428-011-0064-1

De Geus, E. J., and Van Doornen, L. J. (1996). "Ambulatory assessment of parasympathetic/sympathetic balance by impedance cardiography," in Ambulatory assessment: Computer-Assisted Psychological and Psychophysiological Methods in Monitoring and Field Studies, 141-163.

De Santos Sierra, A., Ávila, C. S., Casanova, J. G., and del Pozo, G. B. (2011). A stress-detection system based on physiological signals and fuzzy logic. IEEE Trans. Indus. Electron. 58, 4857-4865. doi: 10.1109/TIE.2010.21 03538

Deng, Y., Yang, M., and Zhou, R. (2017). A new standardized emotional film database for Asian culture. Front. Psychol. 8:1941. doi: 10.3389/fpsyg.2017.01941

Devillers, L., Vidrascu, L., and Lamel, L. (2005). Challenges in real-life emotion annotation and machine learning based detection. Neural Netw. 18, 407-422. doi: 10.1016/j.neunet.2005.03.007

Dhall, A., Goecke, R., Joshi, J., Wagner, M., and Gedeon, T. (2013). "Emotion recognition in the wild challenge 2013," in Proceedings of the 15th ACM on International Conference on Multimodal Interaction (Sydney, NSW: ACM), 509-516. doi: 10.1145/2522848.2531739

Di Cesare, G., Di Dio, C., Marchi, M., and Rizzolatti, G. (2015). Expressing our internal states and understanding those of others. Proc. Natl. Acad. Sci. U.S.A. 112, 10331-10335. doi: 10.1073/pnas.1512133112

Di Cesare, G., Marchi, M., Errante, A., Fasano, F., and Rizzolatti, G. (2017). Mirroring the social aspects of speech and actions: the role of the insula. Cereb. Cortex 28, 1348-1357. doi: 10.1093/cercor/bhx051

Dikecligil, G. N., and Mujica-Parodi, L. R. (2010). Ambulatory and challengeassociated heart rate variability measures predict cardiac responses to real-world acute emotional stress. Biol. Psychiatry 67, 1185-1190. doi: 10.1016/j.biopsych.2010.02.001

Dobbins, C., Fairclough, S., Lisboa, P., and Navarro, F. F. G. (2018). “A lifelogging platform towards detecting negative emotions in everyday life using wearable devices," in 2018 IEEE International Conference on Pervasive Computing and Communications Workshops (PerCom Workshops) (Athens: IEEE), 306-311. doi: 10.1109/PERCOMW.2018.8480180

Eerola, T., and Vuoskoski, J. K. (2011). A comparison of the discrete and dimensional models of emotion in music. Psychol. Music 39, 18-49. doi: 10.1177/0305735610362821

El Ayadi, M., Kamel, M. S., and Karray, F. (2011). Survey on speech emotion recognition: features, classification schemes, and databases. Pattern Recogn. 44, 572-587. doi: 10.1016/j.patcog.2010.09.020

Exler, A., Schankin, A., Klebsattel, C., and Beigl, M. (2016). "A wearable system for mood assessment considering smartphone features and data from mobile ECGs," in Proceedings of the 2016 ACM International Joint Conference on Pervasive and Ubiquitous Computing: Adjunct (ACM), 1153-1161. doi: 10.1145/2968219.29 68302

Fasel, B., and Luettin, J. (2003). Automatic facial expression analysis: a survey. Pattern Recogn. 36, 259-275. doi: 10.1016/S0031-3203(02) 00052-3

Fenz, W. D., and Epstein, S. (1967). Gradients of physiological arousal in parachutists as a function of an approaching jump. Psychosom. Med. 29, 33-51. doi: 10.1097/00006842-196701000-00005

Fox, E., Cahill, S., and Zougkou, K. (2010). Preconscious processing biases predict emotional reactivity to stress. Biol. Psychiatry 67, 371-377. doi: 10.1016/j.biopsych.2009.11.018 
Ge, Z., Prasad, P., Costadopoulos, N., Alsadoon, A., Singh, A., and Elchouemi, A. (2016). "Evaluating the accuracy of wearable heart rate monitors," in 2016 2nd International Conference on Advances in Computing, Communication, \& Automation (ICACCA) (Bareilly: IEEE), 1-6. doi: 10.1109/ICACCAF.2016.7748986

Girard, J. M. (2014). Carma: Software for continuous affect rating and media annotation. J. Open Res. Softw. 2:e5. doi: 10.5334/jors.ar

Gjoreski, M., Gjoreski, H., Luštrek, M., and Gams, M. (2016). "Continuous stress detection using a wrist device: in laboratory and real life," in Proceedings of the 2016 ACM International Joint Conference on Pervasive and Ubiquitous Computing: Adjunct (Heidelberg: ACM), 1185-1193. doi: $10.1145 / 2968219.2968306$

Gjoreski, M., Luštrek, M., Gams, M., and Gjoreski, H. (2017). Monitoring stress with a wrist device using context. J. Biomed. Inform. 73, 159-170. doi: 10.1016/j.jbi.2017.08.006

Gkaintatzis, A., Van Der Lubbe, R., Karantinou, K., and Constantinides, E. (2019). "Consumers' cognitive, emotional and behavioral responses towards background music: an EEG study," in 15th International Conference on Web Information Systems and Technologies, WEBIST 2019 (Vienna: SCITEPRESS), 314-318. doi: 10.5220/0008346603140318

Gray, E. K., and Watson, D. (2001). Emotion, mood, and temperament: similarities, differences, and a synthesis. in Emotions at Work: Theory, Research, and Applications for Management, eds R. L. Payne and C. L. Cooper (Chichester: Wiley), 21-43.

Green, P. J., and Suls, J. (1996). The effects of caffeine on ambulatory blood pressure, heart rate, and mood in coffee drinkers. J. Behav. Med. 19, 111-128. doi: $10.1007 / \mathrm{BF} 01857602$

Grossman, P. (2004). The lifeshirt: a multi-function ambulatory system monitoring health, disease, and medical intervention in the real world. Stud. Health Technol. Inform. 108, 133-141. Available online at: http://ebooks.iospress.nl/ publication/9938

Haiblum-Itskovitch, S., Czamanski-Cohen, J., and Galili, G. (2018). Emotional response and changes in heart rate variability following art-making with three different art materials. Front. Psychol. 9:968. doi: 10.3389/fpsyg.2018. 00968

Harmon-Jones, E., and Sigelman, J. (2001). State anger and prefrontal brain activity: evidence that insult-related relative left-prefrontal activation is associated with experienced anger and aggression. J. Pers. Soc. Psychol. 80:797. doi: 10.1037/0022-3514.80.5.797

Hassellund, S. S., Flaa, A., Sandvik, L., Kjeldsen, S. E., and Rostrup, M. (2010). Long-term stability of cardiovascular and catecholamine responses to stress tests: an 18-year follow-up study. Hypertension 55, 131-136. doi: 10.1161/HYPERTENSIONAHA.109. 143164

Healey, J., Nachman, L., Subramanian, S., Shahabdeen, J., and Morris, M. (2010). "Out of the lab and into the fray: towards modeling emotion in everyday life," in International Conference on Pervasive Computing, vol. 6030, eds P. Floréen, A. Krüger, and M. Spasojevic (Berlin; Heidelberg: Springer), 156-173. doi: 10.1007/978-3-642-12654-3_10

Healey, J., and Picard, R. W. (2005). Detecting stress during real-world driving tasks using physiological sensors. IEEE Trans. Intell. Transport. Syst. 6, 156-166. doi: 10.1109/TITS.2005.848368

Heinisch, J. S., Anderson, C., and David, K. (2019). "Angry or climbing stairs? Towards physiological emotion recognition in the wild," in 2019 IEEE International Conference on Pervasive Computing and Communications Workshops (PerCom Workshops) (Kyoto), 486-491. doi: 10.1109/PERCOMW.2019.8730725

Hernandez, J., Morris, R. R., and Picard, R. W. (2011). "Call center stress recognition with person-specific models," in Affective Computing and Intelligent Interaction. ACII 2011, Lecture Notes in Computer Science, Vol. 6974, eds S. D’Mello, A. Graesser, B. Schuller, and J. C. Martin (Berlin; Heidelberg: Springer), 125-134.

Hirschberg, J., and Manning, C. D. (2015). Advances in natural language processing. Science 349, 261-266. doi: 10.1126/science.aaa8685

Hoque, M. E., McDuff, D. J., and Picard, R. W. (2012). Exploring temporal patterns in classifying frustrated and delighted smiles. IEEE Trans. Affect. Comput. 3, 323-334. doi: 10.1109/T-AFFC.2012.11
Hovsepian, K., Al'Absi, M., Ertin, E., Kamarck, T., Nakajima, M., and Kumar, S. (2015). "cStress: towards a gold standard for continuous stress assessment in the mobile environment," in Proceedings of the 2015 ACM International Joint Conference on Pervasive and Ubiquitous Computing (Osaka: ACM), 493-504. doi: $10.1145 / 2750858.2807526$

Izard, C. E. (1977). Human Emotions. New York, NY: Plenum. doi: 10.1007/978-1-4899-2209-0

Jerritta, S., Murugappan, M., Nagarajan, R., and Wan, K. (2011). "Physiological signals based human emotion recognition: a review," in 2011 IEEE 7th International Colloquium on Signal Processing and its Applications (Penang: IEEE), 410-415. doi: 10.1109/CSPA.2011.5759912

Johnston, D. W., and Anastasiades, P. (1990). The relationship between heart rate and mood in real life. J. Psychosom. Res. 34, 21-27. doi: 10.1016/0022-3999(90)90004-N

Kahneman, D., Diener, E., and Schwarz, N. (1999). Well-Being: Foundations of Hedonic Psychology. Russell Sage Foundation.

Kallinen, K., and Ravaja, N. (2006). Emotion perceived and emotion felt: same and different. Music. Sci. 10, 191-213. doi: 10.1177/102986490601000203

Kanjo, E., Younis, E. M., and Sherkat, N. (2018). Towards unravelling the relationship between on-body, environmental and emotion data using sensor information fusion approach. Inform. Fusion 40, 18-31. doi: 10.1016/j.inffus.2017.05.005

Karlsson, K., Niemelä, P., and Jonsson, A. (2011). Heart rate as a marker of stress in ambulance personnel: a pilot study of the body's response to the ambulance alarm. Prehosp. Disaster Med. 26, 21-26. doi: 10.1017/S1049023X10000129

Karthikeyan, P., Murugappan, M., and Yaacob, S. (2011). "A review on stress inducement stimuli for assessing human stress using physiological signals," in 2011 IEEE 7th International Colloquium on Signal Processing and its Applications (IEEE), 420-425. doi: 10.1109/CSPA.2011.5759914

Kim, J., and André, E. (2008). Emotion recognition based on physiological changes in music listening. IEEE Trans. Pattern Anal. Mach. Intell. 30, 2067-2083. doi: 10.1109/TPAMI.2008.26

Kim, J., and Fesenmaier, D. R. (2015). Measuring emotions in real time: implications for tourism experience design. J. Travel Res. 54, 419-429. doi: 10.1177/0047287514550100

Kim, K. H., Bang, S. W., and Kim, S. R. (2004). Emotion recognition system using short-term monitoring of physiological signals. Med. Biol. Eng. Comput. 42, 419-427. doi: 10.1007/BF02344719

Kimhy, D., Delespaul, P., Ahn, H., Cai, S., Shikhman, M., Lieberman, J. A., et al. (2009). Concurrent measurement of "real-world" stress and arousal in individuals with psychosis: assessing the feasibility and validity of a novel methodology. Schizophrenia Bull. 36, 1131-1139. doi: 10.1093/schbul/sbp028

Kipp, M. (2012). “Chapter 21: Multimedia annotation, querying, and analysis in anvil, in Multimedia Information Extraction: Advances in Video, Audio, and Imagery Analysis for Search, Data Mining, Surveillance, and Authoring, ed M. T. Maybury (John Wiley \& Sons, Ltd), 351-367. doi: 10.1002/9781118219546.ch21

Kleinsmith, A., and Bianchi-Berthouze, N. (2013). Affective body expression perception and recognition: a survey. IEEE Trans. Affect. Comput. 4, 15-33. doi: 10.1109/T-AFFC.2012.16

Kocielnik, R., Sidorova, N., Maggi, F. M., Ouwerkerk, M., and Westerink, J. H. (2013). "Smart technologies for long-term stress monitoring at work," in Proceedings of the 26th IEEE International Symposium on Computer-Based Medical Systems (Porto: IEEE), 53-58. doi: 10.1109/CBMS.2013.6627764

Koelstra, S., Muhl, C., Soleymani, M., Lee, J.-S., Yazdani, A., Ebrahimi, T., et al. (2011). Deap: a database for emotion analysis; using physiological signals. IEEE Trans. Affect. Comput. 3, 18-31. doi: 10.1109/T-AFFC.2011.15

Konečni, V. J. (2008). Does music induce emotion? A theoretical and methodological analysis. Psychol. Aesthet. Creat. Arts 2:115. doi: 10.1037/1931-3896.2.2.115

Kory, J., and D'Mello, S. K. (2015). "Affect elicitation for affective computing," in The Oxford Handbook of Affective Computing, eds R. Calvo, S. D'Mello, J. Gratch, and A. Kappas (New York, NY: Oxford University Press), 371-383. doi: 10.1093/oxfordhb/9780199942237.013.001

Kostis, J., Moreyra, A., Amendo, M., Di Pietro, J., Cosgrove, N., and Kuo, P. (1982). The effect of age on heart rate in subjects free of heart disease. studies by ambulatory electrocardiography and maximal exercise stress test. Circulation 65, 141-145. doi: 10.1161/01.CIR.65.1.141 
Kreibig, S. D. (2010). Autonomic nervous system activity in emotion: a review. Biol. Psychol. 84, 394-421. doi: 10.1016/j.biopsycho.2010.03.010

Kret, M. E., and De Gelder, B. (2012). A review on sex differences in processing emotional signals. Neuropsychologia 50, 1211-1221. doi: 10.1016/j.neuropsychologia.2011.12.022

Kreutz, G., Ott, U., Teichmann, D., Osawa, P., and Vaitl, D. (2008). Using music to induce emotions: Influences of musical preference and absorption. Psychol. Music 36, 101-126. doi: 10.1177/0305735607082623

Kusserow, M., Amft, O., and Tröster, G. (2012a). Modeling arousal phases in daily living using wearable sensors. IEEE Trans. Affect. Comput. 4, 93-105. doi: 10.1109/T-AFFC.2012.37

Kusserow, M., Amft, O., and Tröster, G. (2012b). Monitoring stress arousal in the wild. IEEE Pervas. Comput. 12, 28-37. doi: 10.1109/MPRV.2012.56

Labonte-LeMoyne, É., Courtemanche, F., Fredette, M., and Léger, P. M. (2018). How wild is too wild: lessons learned and recommendations for ecological validity in physiological computing research. In PhyCS. 123-130.

Ladouce, S., Donaldson, D. I., Dudchenko, P. A., and Ietswaart, M. (2017). Understanding minds in real-world environments: toward a mobile cognition approach. Front. Hum. Neurosci. 10:694. doi: 10.3389/fnhum.2016.00694

Lamichhane, B., Großekathofer, U., Schiavone, G., and Casale, P. (2016). "Towards stress detection in real-life scenarios using wearable sensors: normalization factor to reduce variability in stress physiology," in Lecture Notes of the Institute for Computer Sciences, Social Informatics and Telecommunications Engineering (Cham: Springer), 259-270. doi: 10.1007/978-3-319-49655-9_34

Lang, P. J., Bradley, M. M., and Cuthbert, B. N. (2008). International Affective Picture System (IAPS): Affective Ratings of Pictures and Instruction Manual. University of Florida, Gainesville, FL. Technical report, Tech Rep A-8.

Lang, P. J., Kozak, M. J., Miller, G. A., Levin, D. N., and McLean A. Jr. (1980). Emotional imagery: conceptual structure and pattern of somato-visceral response. Psychophysiology 17, 179-192. doi: 10.1111/j.1469-8986.1980.tb00133.x

Larradet, F., Barresi, G., and Mattos, L. S. (2017). "Effects of galvanic skin response feedback on user experience in gaze-controlled gaming: a pilot study," in 2017 39th Annual International Conference of the IEEE Engineering in Medicine and Biology Society (EMBC) (Jeju island: IEEE), 2458-2461. doi: 10.1109/EMBC.2017.80 37354

Larradet, F., Niewiadomski, R., Barresi, G., and Mattos, L. S. (2019). "Appraisal theory-based mobile app for physiological data collection and labelling in the wild," in Proceedings of the 2019 ACM International Joint Conference on Pervasive and Ubiquitous Computing and Proceedings of the 2019 ACM International Symposium on Wearable Computers (London: ACM), 752-756. doi: $10.1145 / 3341162.3345595$

Laurila, J., Gatica-Perez, D., Aad, I., Blom, J., Bornet, O., Do, T.-M.-T, et al. (2012). The Mobile Data Challenge: Big Data for Mobile Computing Research. Nokia Research Center.

Lee, B., Han, J., Baek, H. J., Shin, J. H., Park, K. S., and Yi, W. J. (2010). Improved elimination of motion artifacts from a photoplethysmographic signal using a kalman smoother with simultaneous accelerometry. Physiol. Meas. 31:1585. doi: 10.1088/0967-3334/31/12/003

Lussu, V., Niewiadomski, R., Volpe, G., and Camurri, A. (2019). The role of respiration audio in multimodal analysis of movement qualities. J. Multimodal User Interfaces 14, 1-15. doi: 10.1007/s12193-019-00302-1

Maffei, A., and Angrilli, A. (2019). E-movie - experimental movies for induction of emotions in neuroscience: an innovative film database with normative data and sex differences. PLoS ONE 14:e0223124. doi: 10.1371/journal.pone.02 23124

Markova, V., Ganchev, T., and Kalinkov, K. (2019). CLAS: a database for cognitive load, affect and stress recognition," in 2019 International Conference on Biomedical Innovations and Applications (BIA) (Varna: IEEE), 1-4. doi: 10.1109/BIA48344.2019.8967457

Massot, B., Baltenneck, N., Gehin, C., Dittmar, A., and McAdams, E. (2011). EmoSense: an ambulatory device for the assessment of ANS activity-application in the objective evaluation of stress with the blind. IEEE Sens. J. 12, 543-551. doi: 10.1109/JSEN.2011.2132703

Mauss, I. B., and Robinson, M. D. (2009). Measures of emotion: a review. Cogn. Emot. 23, 209-237. doi: 10.1080/02699930802204677
McDuff, D., Karlson, A., Kapoor, A., Roseway, A., and Czerwinski, M. (2012). "Affectaura: an intelligent system for emotional memory," in Proceedings of the SIGCHI Conference on Human Factors in Computing Systems (Austin, TX: ACM), 849-858. doi: 10.1145/2207676.2208525

Mehrabian, A. (1996). Pleasure-arousal-dominance: a general framework for describing and measuring individual differences in temperament. Curr. Psychol. 14, 261-292. doi: 10.1007/BF02686918

Melanson, E. L., and Freedson, P. S. (2001). The effect of endurance training on resting heart rate variability in sedentary adult males. Eur. J. Appl. Physiol. 85, 442-449. doi: 10.1007/s004210100479

Melhart, D., Liapis, A., and Yannakakis, G. N. (2019). "PAGAN: Video affect annotation made easy," in 2019 8th International Conference on Affective Computing and Intelligent Interaction (ACII) (Cambridge: IEEE), 130-136. doi: 10.1109/ACII.2019.8925434

Melillo, P., Bracale, M., and Pecchia, L. (2011). Nonlinear heart rate variability features for real-life stress detection. Case study: students under stress due to university examination. Biomed. Eng. Online 10:96. doi: 10.1186/1475-925X-10-96

Mesquita, B., Frijda, N. H., and Scherer, K. R. (1997). "Culture and emotion," in Handbook of Cross-Cultural Psychology: Vol. 2. Basic Processes and Human Development, eds J. W. Berry, P. R. Dasen, and T. S. Saraswathi (Boston: Allyn \& Bacon), 255-297.

Muaremi, A., Arnrich, B., and Tröster, G. (2013). Towards measuring stress with smartphones and wearable devices during workday and sleep. BioNanoScience 3, 172-183. doi: 10.1007/s12668-013-0089-2

Muaremi, A., Bexheti, A., Gravenhorst, F., Arnrich, B., and Tröster, G. (2014). "Monitoring the impact of stress on the sleep patterns of pilgrims using wearable sensors," in IEEE-EMBS International Conference on Biomedical and Health Informatics (BHI) (Valencia: IEEE), 185-188. doi: 10.1109/BHI.2014.6864335

Muszynski, M., Kostoulas, T., Lombardo, P., Pun, T., and Chanel, G. (2018). Aesthetic highlight detection in movies based on synchronization of spectators' reactions. ACM Trans. Multimedia Comput. Commun. Appl. 14, 1-23. doi: $10.1145 / 3175497$

Muszynski, M., Tian, L., Lai, C., Moore, J., Kostoulas, T., Lombardo, P., et al. (2019). Recognizing induced emotions of movie audiences from multimodal information. IEEE Trans. Affect. Comput. 1-17. doi: 10.1109/TAFFC.2019.29 02091

Myrtek, M., Aschenbrenner, E., Brügner, G., From the Psychophysiological Research Group at the University of Freiburg (FRG). (2005). Emotions in everyday life: an ambulatory monitoring study with female students. Biol. Psychol. 68, 237-255. doi: 10.1016/j.biopsycho.2004.06.001

Myrtek, M., and Brügner, G. (1996). Perception of emotions in everyday life: studies with patients and normals. Biol. Psychol. 42, 147-164. doi: 10.1016/0301-0511(95)05152-X

Myrtek, M., Fichtler, A., Strittmatter, M., and Brügner, G. (1999). Stress and strain of blue and white collar workers during work and leisure time: results of psychophysiological and behavioral monitoring. Appl. Ergon. 30, 341-351. doi: 10.1016/S0003-6870(98)00031-3

Niewiadomski, R., Mancini, M., Piana, S., Alborno, P., Volpe, G., and Camurri, A. (2017). "Low-intrusive recognition of expressive movement qualities," in Proceedings of the 19th ACM International Conference on Multimodal Interaction, ICMI 2017 (New York, NY: ACM), 230-237. doi: $10.1145 / 3136755.3136757$

Niewiadomski, R., Mancini, M., Varni, G., Volpe, G., and Camurri, A. (2016). Automated laughter detection from full-body movements. IEEE Trans. Hum. Mach. Syst. 46, 113-123. doi: 10.1109/THMS.2015.2480843

Ortony, A., Clore, G. L., and Collins, A. (1990). The Cognitive Structure of Emotions. Cambridge University Press.

Pärkkä, J., Merilahti, J., Mattila, E. M., Malm, E., Antila, K., Tuomisto, M. T., et al. (2008). Relationship of psychological and physiological variables in long-term self-monitored data during work ability rehabilitation program. IEEE Trans. Inform. Technol. Biomed. 13, 141-151. doi: 10.1109/TITB.2008.20 07078

Pasupathi, M. (2003). Emotion regulation during social remembering: differences between emotions elicited during an event and emotions elicited when talking about it. Memory 11, 151-163. doi: 10.1080/741938212 
Pehlivanoğlu, B., Durmazlar, N., and Balkancı, D. (2005). Computer adapted stroop colour-word conflict test as a laboratory stress model. Erciyes Med. J. 27, 58-63. Available online at: http://www.erciyesmedj.com/jvi.aspx?un=EMJ93276

Picard, R. W. (2000). Toward Agents that Recognize Emotion. MIT Media Laboratory Perceptual Computing Session Technical Report No. 515. Available online at: https://www.media.mit.edu/publications/toward-agents-thatrecognize-emotion-2/

Pietilä, J., Mehrang, S., Tolonen, J., Helander, E., Jimison, H., Pavel, M., et al. (2017). "Evaluation of the accuracy and reliability for photoplethysmography based heart rate and beat-to-beat detection during daily activities," in EMBEC \& NBC 2017 (Tempere: Springer), 145-148. doi: 10.1007/978-981-10-5122-7_37

Placidi, G., Polsinelli, M., Spezialetti, M., Cinque, L., Di Giamberardino, P., and Iacoviello, D. (2019). Self-induced emotions as alternative paradigm for driving brain-computer interfaces. Comput. Methods Biomech. Biomed. Eng. Imaging Visual. 7, 512-519. doi: 10.1080/21681163.2018.1479312

Plarre, K., Raij, A., Hossain, S. M., Ali, A. A., Nakajima, M., Al'Absi, M., et al. (2011). "Continuous inference of psychological stress from sensory measurements collected in the natural environment," in Proceedings of the 10th ACM/IEEE International Conference on Information Processing in Sensor Networks (Chicago, IL: IEEE), 97-108.

Rahman, M. M., Bari, R., Ali, A. A., Sharmin, M., Raij, A., Hovsepian, K., et al. (2014). "Are we there yet? Feasibility of continuous stress assessment via wireless physiological sensors," In Proceedings of the 5th ACM Conference on Bioinformatics, Computational Biology, and Health Informatics (Newport beach, CA: ACM), 479-488. doi: 10.1145/2649387.2649433

Ranganathan, H., Chakraborty, S., and Panchanathan, S. (2016). "Multimodal emotion recognition using deep learning architectures," in 2016 IEEE Winter Conference on Applications of Computer Vision (WACV) (Lake Placid, NY: IEEE), 1-9. doi: 10.1109/WACV.2016.7477679

Rani, P., Sims, J., Brackin, R., and Sarkar, N. (2002). Online stress detection using psychophysiological signals for implicit human-robot cooperation. Robotica 20, 673-685. doi: 10.1017/S0263574702004484

Rigas, G., Goletsis, Y., and Fotiadis, D. I. (2011). Real-time driver's stress event detection. IEEE Trans. Intell. Transport. Syst. 13, 221-234. doi: 10.1109/TITS.2011.2168215

Ring, C., Drayson, M., Walkey, D. G., Dale, S., and Carroll, D. (2002). Secretory immunoglobulin a reactions to prolonged mental arithmetic stress: inter-session and intra-session reliability. Biol. Psychol. 59, 1-13. doi: 10.1016/S0301-0511(01)00128-4

Robinson, M. D., and Clore, G. L. (2001). Simulation, scenarios, and emotional appraisal: testing the convergence of real and imagined reactions to emotional stimuli. Pers. Soc. Psychol. Bull. 27, 1520-1532. doi: $10.1177 / 01461672012711012$

Robinson, M. D., and Clore, G. L. (2002). Belief and feeling: evidence for an accessibility model of emotional self-report. Psychol. Bull. 128:934. doi: 10.1037/0033-2909.128.6.934

Rooney, B., Benson, C., and Hennessy, E. (2012). The apparent reality of movies and emotional arousal: a study using physiological and self-report measures. Poetics 40, 405-422. doi: 10.1016/j.poetic.2012.07.004

Roseman, I. J. (1984). Cognitive determinants of emotion: a structural theory. Rev. Pers. Soc. Psychol. 5, 11-36.

Roseway, A., Lutchyn, Y., Johns, P., Mynatt, E., and Czerwinski, M. (2015). Biocrystal: an ambient tool for emotion and communication. Int. J. Mobile Hum. Comput. Interact. 7, 20-41. doi: 10.4018/ijmhci.2015070102

Russell, J. A. (1980). A circumplex model of affect. J. Pers. Soc. Psychol. 39:1161. doi: $10.1037 / \mathrm{h} 0077714$

Sabatinelli, D., Frank, D., and Filkowski, M. (2017). "Emotional networks in the brain," in Encyclopedia of Personality and Individual Differences (1st ed.), eds V. Zeigler-Hill and T. Shackelford (New York, NY: Springer International Publishing), 1-10.

Salimpoor, V. N., van den Bosch, I., Kovacevic, N., McIntosh, A. R., Dagher, A., and Zatorre, R. J. (2013). Interactions between the nucleus accumbens and auditory cortices predict music reward value. Science 340, 216-219. doi: $10.1126 /$ science. 1231059

Sarker, H., Tyburski, M., Rahman, M. M., Hovsepian, K., Sharmin, M., Epstein, D. H., et al. (2016). "Finding significant stress episodes in a discontinuous time series of rapidly varying mobile sensor data," in Proceedings of the $2016 \mathrm{CHI}$
Conference on Human Factors in Computing Systems (San Jose, CA: ACM), 4489-4501. doi: 10.1145/2858036.2858218

Schaefer, A., Nils, F., Sanchez, X., and Philippot, P. (2010). Assessing the effectiveness of a large database of emotion-eliciting films: a new tool for emotion researchers. Cogn. Emot. 24, 1153-1172. doi: 10.1080/02699930903274322

Schmidt, K., Patnaik, P., and Kensinger, E. A. (2011). Emotion's influence on memory for spatial and temporal context. Cogn. Emot. 25, 229-243. doi: 10.1080/02699931.2010.483123

Schmidt, P., Dürichen, R., Reiss, A., Van Laerhoven, K., and Plötz, T. (2019). "Multi-target affect detection in the wild: an exploratory study," in Proceedings of the 23rd International Symposium on Wearable Computers (London), 211-219. doi: 10.1145/3341163.3347741

Schmidt, P., Reiss, A., Dürichen, R., and Van Laerhoven, K. (2018). "Labelling affective states in the wild: practical guidelines and lessons learned," in Proceedings of the 2018 ACM International Joint Conference and 2018 International Symposium on Pervasive and Ubiquitous Computing and Wearable Computers (Singapore: ACM), 654-659. doi: 10.1145/3267305.3267551

Schoeller, F., Bertrand, P., Gerry, L. J., Jain, A., Horowitz, A. H., and Zenasni, F. (2019). Combining virtual reality and biofeedback to foster empathic abilities in humans. Front. Psychol. 9:2741. doi: 10.3389/fpsyg.2018.02741

Sharma, K., Castellini, C., Broek, E. L., Albu-Schaeffer, A., and Schwenker, F. (2018). A dataset of continuous affect annotations and physiological signals for emotion analysis. arXiv[Preprint].arXiv:1812.02782. doi: 10.1038/s41597-019-0209-0

Shiffman, S., Stone, A. A., and Hufford, M. R. (2008). Ecological momentary assessment. Annu. Rev. Clin. Psychol. 4, 1-32. doi: 10.1146/annurev.clinpsy.3.022806.091415

Shu, L., Xie, J., Yang, M., Li, Z., Li, Z., Liao, D., Xu, X., and Yang, X. (2018). A review of emotion recognition using physiological signals. Sensors 18:2074. doi: 10.3390/s18072074

Skowron, M., Rank, S., Garcia, D., and Hołyst, J. A. (2017). “Zooming in: studying collective emotions with interactive affective systems," in Cyberemotions (Springer), 279-304. doi: 10.1007/978-3-319-43639-5_14

Smith, E., and Delargy, M. (2005). Locked-in syndrome. BMJ 330, 406-409. doi: $10.1136 /$ bmj.330.7488.406

Snyder, J., Matthews, M., Chien, J., Chang, P. F., Sun, E., Abdullah, S., et al. (2015). "Moodlight: exploring personal and social implications of ambient display of biosensor data," in Proceedings of the 18th ACM Conference on Computer Supported Cooperative Work \& Social Computing (Vancouver, BC: ACM), 143-153. doi: 10.1145/2675133.2675191

Soleymani, M., Lichtenauer, J., Pun, T., and Pantic, M. (2011). A multimodal database for affect recognition and implicit tagging. IEEE Trans. Affect. Comput. 3, 42-55. doi: 10.1109/T-AFFC.2011.25

Stroop, J. R. (1935). Studies of interference in serial verbal reactions. J. Exp. Psychol. 18:643. doi: 10.1037/h0054651

Tognetti, S., Garbarino, M., Bonanno, A. T., Matteucci, M., and Bonarini, A. (2010). "Enjoyment recognition from physiological data in a car racing game," in Proceedings of the 3rd International Workshop on Affective Interaction in Natural Environments (Firenze: ACM), 3-8. doi: 10.1145/1877826.1877830

Tomkins, S. (1962). Affect Imagery Consciousness: Volume I: The Positive Affects. Springer publishing company.

Torres, J. M. M., Ghosh, A., Stepanov, E. A., and Riccardi, G. (2016). "Heal-T: an efficient PPG-based heart-rate and IBI estimation method during physical exercise," in 2016 24th European Signal Processing Conference (EUSIPCO) (Budapest: IEEE), 1438-1442. doi: 10.1109/EUSIPCO.2016.7760486

Tschacher, W., Greenwood, S., Kirchberg, V., Wintzerith, S., van den Berg, K., and Tröndle, M. (2012). Physiological correlates of aesthetic perception of artworks in a museum. Psychol. Aesthet. Creat. Arts. 6, 96-103. doi: 10.1037/a0023845

Turner-Cobb, J. M., Asif, M., Turner, J. E., Bevan, C., and Fraser, D. S. (2019). Use of a non-human robot audience to induce stress reactivity in human participants. Comput. Hum. Behav. 99, 76-85. doi: 10.1016/j.chb.2019. 05.019

Valstar, M. (2019). "Multimodal databases," in The Handbook of MultimodalMultisensor Interfaces: Language Processing, Software, Commercialization, and Emerging Directions - Volume 3. Association for Computing Machinery and Morgan \& Claypool, 393-421. doi: 10.1145/3233795.3233807 
Verkuil, B., Brosschot, J. F., Tollenaar, M. S., Lane, R. D., and Thayer, J. F. (2016). Prolonged non-metabolic heart rate variability reduction as a physiological marker of psychological stress in daily life. Ann. Behav. Med. 50, 704-714. doi: 10.1007/s12160-016-9795-7

Ververidis, D., Kotsia, I., Kotropoulos, C., and Pitas, I. (2008). "Multi-modal emotion-related data collection within a irtual earthquake emulator," in Programme of the Workshop on Corpora for Research on Emotion and Affect (Marrakech Morocco), 57.

Vila, G., Godin, C., Sakri, O., Labyt, E., Vidal, A., Charbonnier, S., et al. (2019). Real-time monitoring of passenger's psychological stress. Future Internet 11:102. doi: 10.3390/fil1050102

Von Dawans, B., Kirschbaum, C., and Heinrichs, M. (2011). The trier social stress test for groups (TSST-G): a new research tool for controlled simultaneous social stress exposure in a group format. Psychoneuroendocrinology 36, 514-522. doi: 10.1016/j.psyneuen.2010.08.004

Vrana, S. R. (1993). The psychophysiology of disgust: differentiating negative emotional contexts with facial EMG. Psychophysiology 30, 279-286. doi: 10.1111/j.1469-8986.1993.tb03354.x

Vuoskoski, J. K., and Eerola, T. (2011). Measuring music-induced emotion: a comparison of emotion models, personality biases, and intensity of experiences. Music. Sci. 15, 159-173. doi: 10.1177/1029864911015 00203

Wac, K., and Tsiourti, C. (2014). Ambulatory assessment of affect: survey of sensor systems for monitoring of autonomic nervous systems activation in emotion. IEEE Trans. Affect. Comput. 5, 251-272. doi: 10.1109/TAFFC.2014.23 32157

Wallbott, H. G., and Scherer, K. R. (1986). Cues and channels in emotion recognition. J. Pers. Soc. Psychol. 51:690. doi: 10.1037/0022-3514.51. 4.690

Walter, S., Scherer, S., Schels, M., Glodek, M., Hrabal, D., Schmidt, M., et al. (2011). "Multimodal emotion classification in naturalistic user behavior," in International Conference on Human-Computer Interaction (Orlando, FL: Springer), 603-61. doi: 10.1007/978-3-642-21616-9_68

Watson, J., Sargent, A., Topoglu, Y., Ye, H., Zhong, W., Suri, R., et al. (2019). "Using fNIRS and EDA to investigate the effects of messaging related to a dimensional theory of emotion," in International Conference on Applied Human Factors and Ergonomics (Springer), 59-67. doi: 10.1007/978-3-030-204 73-0_6

Wettstein, A., Kühne, F., Tschacher, W., and La Marca, R. (2020). Ambulatory assessment of psychological and physiological stress on workdays and free days among teachers. A preliminary study. Front. Neurosci. 14:112. doi: $10.3389 /$ fnins. 2020.00112

Widen, S. C., and Russell, J. A. (2010). Descriptive and prescriptive definitions of emotion. Emot. Rev. 2, 377-378. doi: 10.1177/17540739103 74667

Wilhelm, F. H., and Grossman, P. (2010). Emotions beyond the laboratory: theoretical fundaments, study design, and analytic strategies for advanced ambulatory assessment. Biol. Psychol. 84, 552-569. doi: 10.1016/j.biopsycho.2010.01.017
Wilhelm, F. H., Pfaltz, M. C., and Grossman, P. (2005). Continuous electronic data capture of physiology, behavior and experience in real life: towards ecological momentary assessment of emotion. Interact. Comput. 18, 171-186. doi: 10.1016/j.intcom.2005.07.001

Wilhelm, F. H., and Roth, W. T. (1998). Using minute ventilation for ambulatory estimation of additional heart rate. Biol. Psychol. 49, 137-150. doi: 10.1016/S0301-0511(98)00032-5

Woodward, K., Kanjo, E., Brown, D., McGinnity, T. M., Inkster, B., Macintyre, D. J., Tsanas, A. (2019). Beyond mobile apps: a survey of technologies for mental well-being. IEEE Trans. Affect. Comput. 1-20.

Xu, Y., Hübener, I., Seipp, A.-K., Ohly, S., and David, K. (2017). "From the lab to the real-world: an investigation on the influence of human movement on emotion recognition using physiological signals," in 2017 IEEE International Conference on Pervasive Computing and Communications Workshops (PerCom Workshops) (Honolulu, HI: IEEE), 345-350.

Yin, L., Wei, X., Sun, Y., Wang, J., and Rosato, M. J. (2006). “A 3D facial expression database for facial behavior research," in 7th International Conference on Automatic Face and Gesture Recognition (FGR06) (Southampton: IEEE), 211-216.

Zajonc, R. B., Murphy, S. T., and Inglehart, M. (1989). Feeling and facial efference: implications of the vascular theory of emotion. Psychol. Rev. 96:395. doi: 10.1037/0033-295X.96.3.395

Zenonos, A., Khan, A., Kalogridis, G., Vatsikas, S., Lewis, T., and Sooriyabandara, M. (2016). "Healthyoffice: mood recognition at work using smartphones and wearable sensors," in 2016 IEEE International Conference on Pervasive Computing and Communication Workshops (PerCom Workshops) (Sydney, NSW: IEEE), 1-6. doi: 10.1109/PERCOMW.2016.7457166

Zhai, J., and Barreto, A. (2006). "Stress detection in computer users based on digital signal processing of noninvasive physiological variables," in 2006 International Conference of the IEEE Engineering in Medicine and Biology Society (New York City, NY: IEEE), 1355-1358. doi: 10.1109/IEMBS.2006.259421

Zhang, J., Tang, H., Chen, D., and Zhang, Q. (2012). "destress: Mobile and remote stress monitoring, alleviation, and management platform," in 2012 IEEE Global Communications Conference (GLOBECOM) (Anaheim, CA: IEEE), 2036-2041.

Zhao, M., Adib, F., and Katabi, D. (2016). "Emotion recognition using wireless signals," in Proceedings of the 22nd Annual International Conference on Mobile Computing and Networking, 95-108. doi: 10.1145/2973750.2973762

Conflict of Interest: The authors declare that the research was conducted in the absence of any commercial or financial relationships that could be construed as a potential conflict of interest.

Copyright (c) 2020 Larradet, Niewiadomski, Barresi, Caldwell and Mattos. This is an open-access article distributed under the terms of the Creative Commons Attribution License (CC BY). The use, distribution or reproduction in other forums is permitted, provided the original author(s) and the copyright owner(s) are credited and that the original publication in this journal is cited, in accordance with accepted academic practice. No use, distribution or reproduction is permitted which does not comply with these terms. 